\title{
OxyR and SoxR Modulate the Inducible Oxidative Stress Response and Are Implicated During Different Stages of Infection for the Bacterial Phytopathogen Pantoea stewartii subsp. stewartii
}

\author{
Lindsey Burbank and M. Caroline Roper \\ Department of Plant Pathology and Microbiology, 900 University Avenue, University of California, Riverside, CA 92521, U.S.A.
}

Submitted 20 November 2013. Accepted 1 January 2014.

\begin{abstract}
Reactive oxygen species (ROS) from a variety of sources are often encountered by invading plant pathogens during the infection process. Pantoea stewartii subsp. stewartii, the etiological agent of Stewart's wilt, is a serious bacterial pathogen of sweet corn that colonizes both the apoplast and xylem tissues in which ROS are produced. The $P$. stewartii genome predicts the presence of two redox-sensing transcriptional regulators, OxyR and SoxR, which both activate gene expression in response to oxidative stress. ROS exposure in the form of hydrogen peroxide and the superoxide-generating compound paraquat initiates an induced stress response through OxyR and SoxR that includes activation of the ROS-detoxifying enzymes alkyl hydroperoxide reductase and superoxide dismutase. $P$. stewartii $\Delta s o x R$ was more sensitive to paraquat and was compromised in the ability to form water-soaked lesions, while $\Delta o x y R$ was more sensitive to hydrogen peroxide treatment and was deficient in exopolysaccharide production and the elicitation of wilting symptoms. This demonstrates that both SoxR and OxyR play an important role in virulence in the different niches that $\boldsymbol{P}$. stewartii colonize during the infection process.
\end{abstract}

Pantoea stewartii subsp. stewartii, a gram-negative bacterium belonging to the Enterobacteriaceae family, is the causal agent of Stewart's wilt disease of sweet corn (Zea mays). P. stewartii is a quarantined pathogen worldwide and causes significant damage to susceptible sweet corn varieties in the north-central and eastern United States (Pataky 2003; Roper 2011). This bacterium is carried by the corn flea beetle (Chaetocnema pulicaria), which transmits the pathogen by depositing it into the plant tissue via its feeding wounds (Claflin 1999). In susceptible young seedlings, Stewart's wilt consists of a leaf blight phase and a severe wilting phase. During the leaf blight phase, characteristic water-soaked lesions form as the bacteria colonize the leaf apoplast. Subsequently, the bacteria preferentially colonize the xylem tissue, in which they

Corresponding author: M. C. Roper; E-mail: mcroper@ucr.edu

* The $\boldsymbol{e}$-Xtra logo stands for "electronic extra" and indicates that a supplementary figure is available online.

(C) 2014 The American Phytopathological Society produce large amounts of stewartan exopolysaccharide (EPS) and form biofilms. It is these biofilms and the associated EPS that cause vessel blockage, which leads to the wilting symptoms observed in young susceptible seedlings (Braun 1982).

We demonstrate here that there are also significant amounts of reactive oxygen species (ROS) in the water-soaked lesions associated with Stewart's wilt that are likely a result of plant cell leakage from the ruptured cells that form the lesions. Another important source of ROS, specifically in xylem tissue, comes from differentiating thin-walled xylem cells and nonlignifying xylem parenchyma cells that are capable of sustained production of $\mathrm{H}_{2} \mathrm{O}_{2}$, which can accumulate and diffuse widely between neighboring xylem elements (Barceló 2005). This $\mathrm{H}_{2} \mathrm{O}_{2}$ is important for the cross-linking that occurs during the lignification process in developing xylem elements. Additionally, plant hosts have exploited the bacterium's vulnerability to ROS by generating ROS and redox-cycling compounds as part of the oxidative burst associated with the plant defense response (Apel and Hirt 2004; Buchanan et al. 2000; Lamb and Dixon 1997). Therefore, $P$. stewartii encounters potentially significant amounts of either ROS, redox-cycling compounds, or both during both the apoplastic and xylem phases of infection, making response to and protection against oxidative stress an important aspect of pathogenesis for P. stewartii.

ROS can be toxic to bacterial cells and cause damage to proteins, lipids, and nucleic acids (Cabiscol et al. 2000). Because of their potentially detrimental effects, bacteria have evolved defense mechanisms to combat ROS, including production of ROS-detoxifying enzymes, DNA repair, and sequestration of metal ions (Storz et al. 1990). Bacteria maintain basal oxidative stress defenses but, also, possess a highly inducible oxidative stress response largely controlled by redox-sensing transcription factors that act as redox-operated genetic switches to activate genes involved in the oxidative stress response. Two of these redox-sensing transcription factors, OxyR and SoxR, have been characterized in a number of bacterial species, and orthologs of both are found in the P. stewartii genome (FloresCruz and Allen 2011; Imlay 2008; Mahavihakanont et al. 2012; Pomposiello and Demple 2001; Storz et al. 1990). OxyR is a DNA-binding transcription factor that is activated under oxidizing conditions by the formation of a disulfide bond between two cysteine residues (Zheng et al. 1998). When activated, OxyR binds to DNA as a tetramer and mediates the cellular response to hydrogen peroxide. The OxyR regulon includes production of catalases and other detoxifying enzymes as well as 
proteins involved in DNA repair and iron homeostasis (Cabiscol et al. 2000; Flores-Cruz and Allen 2011; Mukhopadhyay and Schellhorn 1997; Storz et al. 1990; Zheng et al. 1999). OxyR also regulates specific virulence factors, such as the surface adhesion, Ag43 in Escherichia coli and fimbriae in Serratia marcescens that contribute to biofilm formation (Henderson and Owen 1999; Shanks et al. 2007). The SoxR/S system has been well characterized in enterics, such as Escherichia coli and Salmonella typhimurium (Fang et al. 1997; Liochev et al. 1999). SoxR and SoxS are both transcriptional activators that partner in sensing oxidative stress. SoxR belongs to the MerR family of transcriptional regulators and can sense superoxides and superoxide-generating compounds via one-electron oxidation of its iron sulfur cluster ( $\mathrm{Gu}$ and Imlay 2011; Mahavihakanont et al. 2012; Pomposiello and Demple 2001). In enteric bacteria, the primary target of SoxR is soxS, which encodes the DNA binding transcriptional activator SoxS (Wu and Weiss 1992). The SoxS regulon aids in restoring the oxidant balance within the cell. In this two-step activation cascade, the SoxR/S system collectively prevents or repairs damage inflicted by superoxide stress and includes genes encoding superoxidescavenging enzymes, such as superoxide dismutase (SOD) (Imlay 2008; Wu and Weiss 1992). Activation of the SoxR/S system also confers resistance to nitric oxide, organic solvents, and some antibiotics (Chou et al. 1993; Greenberg et al. 1990).

In this study, we demonstrate that $P$. stewartii defends itself from oxidative stress via the redox-sensing transcriptional regulators OxyR and SoxR, in part, through the induced expression of ROS-detoxifying enzymes. In addition to mediating a facet of the oxidative stress response, we also demonstrate that OxyR either directly or indirectly regulates EPS production, a critical virulence factor for P. stewartii. Most importantly, these two global regulators are necessary for full virulence, either in the apoplast or xylem, respectively, highlighting the importance of these redox-responsive transcriptional regulators during the infection process in compatible $P$. stewartii-sweet corn interactions.

\section{RESULTS}

\section{Protein domain analysis of OxyR and SoxR.}

The 305-aa P. stewartii OxyR protein shares $99 \%$ identity to Pantoea ananatis 5342 OxyR $(\mathrm{E}=0.0)$. Based on the Conserved Domain Database, this protein contains an $\mathrm{N}$-terminal helix-turn-helix domain for its DNA binding activity and a Cterminal dimerization domain characteristic of the LysR family of transcriptional regulators (Marchler-Bauer et al. 2013). This C-terminal region also contains two conserved redox-active cysteine residues that are responsible for its oxidative-stress sensing ability (Kullik et al. 1995).

P. stewartii SoxR is a 161 -aa protein with $96 \%$ identity to Pantoea ananatis LMG $201203(\mathrm{E}=2 \mathrm{e}-109)$ SoxR. P. stewartii SoxR contains a conserved N-terminal helix-turn-helix DNA binding domain consistent with other MerR family transcription factors, in addition to a C-terminal iron-sulfur cluster responsible for its redox-sensing function (Marchler-Bauer et al. 2013). Activation of SoxR and its ability to bind DNA are dependent on the redox state of the iron-sulfur cluster (Gaudu and Weiss 1996).

\section{$P$. stewartii infected leaves contain ROS.}

$3^{\prime} 3^{\prime}$-diaminobenzidine (DAB) polymerizes instantly and forms a dark-brown precipitate in the presence of $\mathrm{H}_{2} \mathrm{O}_{2}$, with a detection threshold of $100 \mu \mathrm{M}$. This technique allows for in situ detection of $\mathrm{H}_{2} \mathrm{O}_{2}$ (Thordal-Christensen et al. 1997). At 3 days postinoculation, DAB staining of infected leaf tissue (when visible water-soaked lesions started to form) showed dark-brown areas that corresponded to the locations of the water-soaked lesions, indicating the presence of $\mathrm{H}_{2} \mathrm{O}_{2}$ within the lesions (Fig 1A). There was very minimal brown precipitate associated with buffer-inoculated plant tissue, which likely resulted from the manipulation of the plant tissue inherent to the technique (Fig. 1B). Nitro blue tetrazolium (NBT) forms a dark-blue reaction product when reduced by superoxide anions. This staining procedure can be highly sensitive, detecting amounts of superoxide as low as $4 \mathrm{nmol}$ per milligram of leaf tissue (GrelletBournonville and Díaz-Ricci 2011). We observed dark-blue areas within water-soaked lesions, indicating the presence of superoxide anions in infected tissue (Fig. 1C). A small number of faint blue areas were visible in mock-inoculated plant tissues, which were likely due to the manipulation of the plant tissue inherent to the technique (Fig. 1D). These data, taken together, indicate that $P$. stewartii is exposed to high levels of ROS that could potentially incite oxidative stress in the apoplast during water-soaked lesion formation. We also sought to determine if ROS were present in sweet corn leaves $1 \mathrm{~h}$ postinfection (before lesion formation occurs), to assess whether significant amounts of ROS accumulate early in the infection process, which would be indicative of an oxidative burst. However, we did not detect the presence of ROS $1 \mathrm{~h}$ postinfection in whorl-inoculated plants, using either the DAB or NBT staining methods (data not shown). This suggests that an effective oxidative burst does not occur during the compatible $P$. stewartii-sweet corn interaction or the level of ROS was below the threshold of detection.

\section{SoxR and OxyR protect against oxidative stress in vitro.}

We challenged both $\triangle o x y R$ and $\Delta s o x R$ mutants with exogenous $\mathrm{H}_{2} \mathrm{O}_{2}$ or paraquat (a superoxide generator) to determine the contributions of OxyR and SoxR to combating these two forms of ROS. We determined that $\Delta o x y R$ was significantly more sensitive to $\mathrm{H}_{2} \mathrm{O}_{2}$ compared with wild type, using a disc diffusion assay (Fig. 2A and B). In the wild type, the size of the inhibition zone measured from the edge of the paper disc was $0.81 \pm 0.02 \mathrm{~cm}$, whereas for $\Delta o x y R$, it was $1.60 \pm 0.02 \mathrm{~cm}$, which was significantly different based on a Student's $t$-test using $P \leq 0.02$ (Fig. 2B). This phenotype was restored by complementation with a wild-type copy of $o x y R$. In contrast, the $\Delta$ soxR mutant was similarly as tolerant to $\mathrm{H}_{2} \mathrm{O}_{2}$ as the wildtype parent strain, with an inhibition zone of $0.80 \pm 0.02 \mathrm{~cm}$, indicating that OxyR and not SoxR contributes to tolerance of $\mathrm{H}_{2} \mathrm{O}_{2}$ (Fig. 2A and B).

When grown in the presence of $100 \mu \mathrm{M}$ paraquat, wild-type $P$. stewartii showed, on average, a survival rate of $41 \%$ compared with the untreated control. The $\Delta$ sox $R$ mutant had a significantly reduced survival rate of $0.2 \%$, based on a Student's $t$-test $(P \leq 0.02)$, compared with the untreated control, indicating that this strain was more sensitive to paraquat treatment than the wild-type parent strain (Fig. 3). The complemented $\Delta \operatorname{soxR}$ strain $(\Delta \operatorname{soxR} / \operatorname{soxR}+)$ showed partial restoration of the wild-type phenotype, with a survival rate of $36 \%$. The $\Delta o x y R$ mutant exhibited a survival rate of $27 \%$ compared with the untreated control, which was not significantly different from the wild type, indicating that OxyR is not largely involved in the response to superoxide-generating compounds (Fig. 3).

In $E$. coli, the SoxR/S regulon has also been implicated in response to other stressors, such as nitric oxide stress (Nunoshiba et al. 1993, 1995; Pullan et al. 2007). However, when treated with either 10 or $30 \mu \mathrm{M}$ NOC-5 (3-[aminopropyl]-1-hydroxy-3-isopropyl-2-oxo-1-triazene), a nitric oxidegenerating compound, there was no significant difference between the survival of $\Delta s o x R$ and the wild type (Supplementary Fig. 1). This indicates that the SoxR-mediated oxidative stress response is not important for nitric oxide tolerance in P. stewartii under the growth conditions measured. Similar results 
have been observed in S. typhimurium, in which SoxR was shown to be important for resistance to paraquat but not to nitric oxide-generating compounds (Fang et al. 1997).

\section{OxyR and SoxR regulate expression of ROS-detoxifying enzymes.}

An important component of the inducible bacterial oxidative stress response is the production of ROS-detoxifying enzymes, such as catalases, peroxidases, and SOD. Specifically, in $S$. typhimurium, OxyR positively regulates the expression of ahpC (alkyl hydroperoxide reductase), katG (catalase/hydroperoxidase) and gorA (glutathione oxidoreductase) (Christman et al. 1985). In E. coli, OxyR strongly induces expression of $a h p C$, one of the primary peroxide scavenging enzymes (Seaver and Imlay 2001) as well as the catalase katG (Schellhorn 1994). Analysis of the $P$. stewartii genome revealed at least four genes with high homology to catalases, at least five putative peroxidase enzymes, and one glutathione oxidoreductase (Glasner et al. 2006). Additionally, in the P. stewartii genome, there is an $a h p C$ gene orthologous to $\operatorname{ahpC}$ found in $S$. enterica CFSAN002050 (GenBank accession number CP006055.1, $81 \%$ similarity, and $\mathrm{E}=2 \mathrm{e}-124)$. In $E$. coli, the SoxR/S regulon includes sodA (manganese SOD), fpr (NADPH:ferridoxin reductase), and $n f s A$ (nitrate reductase $\mathrm{A}$ ), among other general stress-response genes (Manchado et al. 2000, Tsaneva and Weiss 1990). P. stewartii possesses an ortholog to sodA with high homology to sodA found in S. enterica CFSAN002050 (GenBank accession number CP006055.1, 82\% similarity and $\mathrm{E}=1 \mathrm{e}-137)$.

We chose to quantify expression of $a h p C$ and $\operatorname{sod} A$ as indicators of induced enzyme expression in response to oxidative stress, as well as soxS, a well-known induced target of SoxR

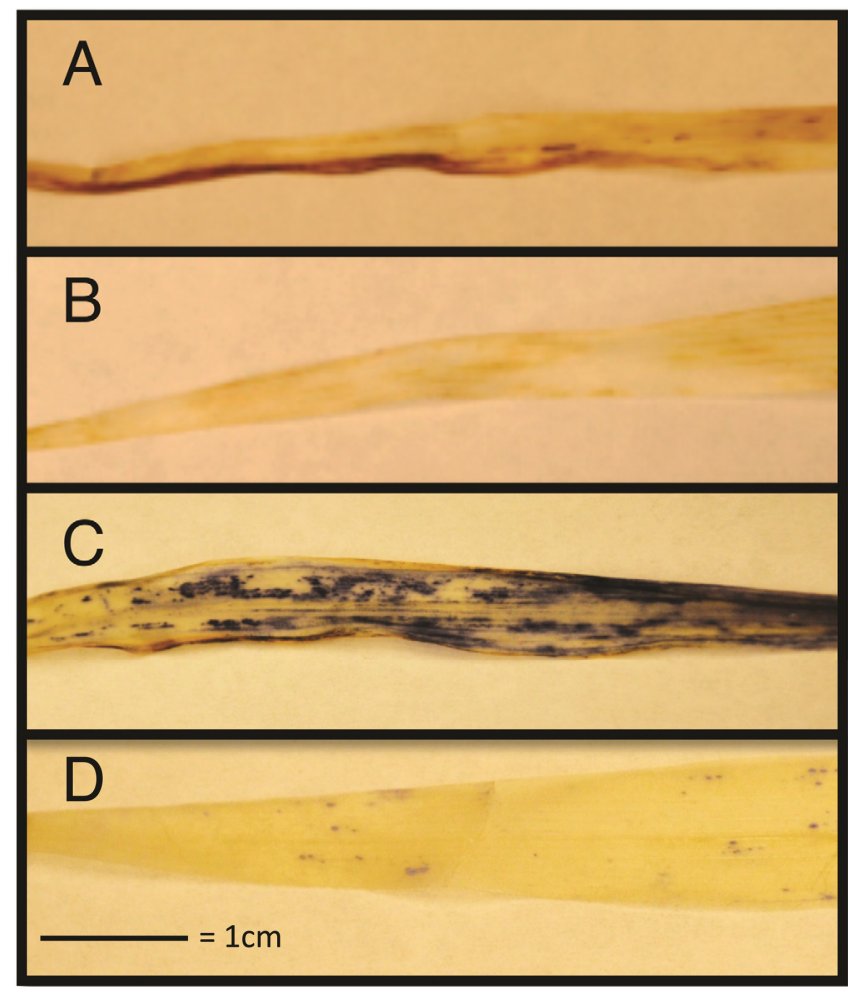

Fig. 1. Reactive oxygen species are present in water-soaked lesions. A, Wildtype DC283-inoculated leaves stained with 3'3'-diaminobenzidine (DAB). B, Mock-inoculated leaves stained with DAB. C, Wild-type DC283-inoculated leaves stained with nitroblue tetrazolium (NBT), D, Mock-inoculated leaves stained with NBT. Leaves were harvested 3 days postinoculation and were stained overnight with either DAB or NBT, and chlorophyll was removed by boiling in acetic acid, glycerol, and ethanol (1:1:3) for $10 \mathrm{~min}$.
(Wu and Weiss 1992), which acts as an intermediate in SoxR regulation. Following $\mathrm{H}_{2} \mathrm{O}_{2}$ treatment, we observed a fourfold induction of $a h p C$ expression in wild-type $P$. stewartii. This induction was lost in $\Delta o x y R$, indicating that peroxide-induced expression of $a h p C$ is OxyR-dependent in P. stewartii (Fig. 4A). Interestingly, $\operatorname{ahpC}$ expression was also significantly induced following $\mathrm{H}_{2} \mathrm{O}_{2}$ treatment in the $\Delta$ sox $R$ mutant and was, in fact, expressed at levels 23 -fold higher than in $\Delta$ soxR untreated cells, as compared with only a fourfold induction in wild-type $\mathrm{H}_{2} \mathrm{O}_{2}$-treated cells. This could indicate that SoxR suppresses $a h p C$ induction in the response to $\mathrm{H}_{2} \mathrm{O}_{2}$. Alternatively, because $a h p C$ expression was also induced by paraquat treatment in wild-type $P$. stewartii and the $\Delta$ soxR mutant, we speculate that the observed increase in $\operatorname{ahpC}$ expression could be due to the generation of intracellular reactive oxygen intermediates that result from the disturbance in the overall redox status of the cell imposed by treatment with paraquat rather than derepression of $a h p C$ by SoxR. We postulate that the lack of a functioning SoxR/S system exacerbates the disturbance in the redox status of the cell in the $\Delta$ sox $R$ mutant, which in turn, creates a more oxidative environment. Oxidized OxyR is the active form of the protein (Zheng et al. 1998, 2001) and an increase in endogenous oxidative stress could potentially lead to an increase in oxidized and activation form of OxyR. This, in turn, would result in the increase in transcription of $a h p C$ observed in the $\Delta$ soxR mutant under oxidative conditions following both $\mathrm{H}_{2} \mathrm{O}_{2}$ and paraquat treatments.

In paraquat-treated samples of wild-type $P$. stewartii, expression of $\operatorname{sodA}$ was induced 6.5-fold (Fig. 4B). As expected, this induction was SoxR-dependent. There were no differ-
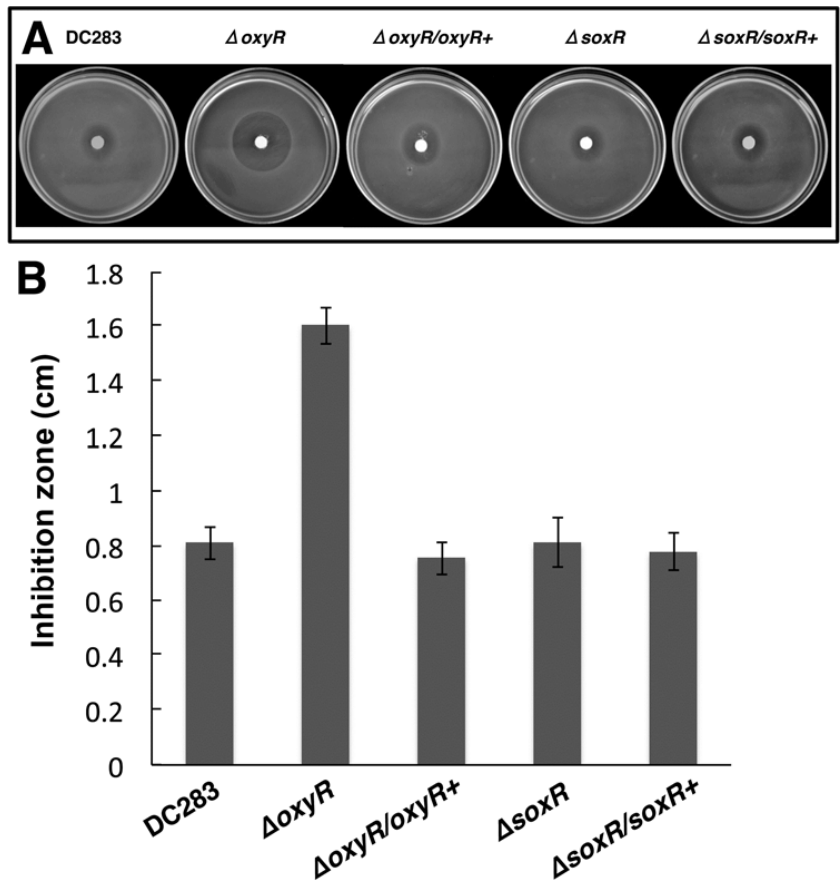

Fig. 2. $\triangle o x y R$ is more sensitive to hydrogen peroxide. Strains were grown to mid-log phase (optical density at $600 \mathrm{~nm}=0.5$ ) in Luria Bertani medium. This cell suspension $(300 \mu \mathrm{l})$ was mixed with $3 \mathrm{ml}$ of $0.8 \%$ nutrient top agar and was overlaid onto nutrient agar containing nalidixic acid $(30 \mu \mathrm{g} / \mathrm{ml})$. A Whatman paper disk treated with $10 \mu \mathrm{l}$ of $100 \mathrm{mM} \mathrm{H}_{2} \mathrm{O}_{2}$ was placed in the center of the plate. A, Images were taken following $24 \mathrm{~h}$ of incubation at $28^{\circ} \mathrm{C}$. B, Quantitative measurements of the zone of growth inhibition surrounding the $\mathrm{H}_{2} \mathrm{O}_{2}$-treated disk measured following $24 \mathrm{~h}$ of incubation at $28^{\circ} \mathrm{C}$. The graph represents the mean of at least nine replicates. Bars labeled with different letters are significantly different based on a Student's $t$-test $(P \leq 0.02)$. Error bars $=$ standard error of the mean. 
ences in the relative amounts of $\operatorname{sod} A$ expression when comparing $\mathrm{H}_{2} \mathrm{O}_{2}$-treated with untreated cells in wild type, $\Delta o x y R$, or $\Delta$ soxR, indicating that $\mathrm{H}_{2} \mathrm{O}_{2}$ is not a potent inducer of sodA expression (Fig. 4A). Paraquat treatment induced soxS expression 31-fold in wild-type cells and this induction was SoxR-dependent (Fig. 4B). The expression of soxS was also induced (17.8-fold) in the $\Delta o x y R$ mutant in a trend similar to the wild type, although the ratio was lower. However, the basal level of soxS expression was slightly higher in the $\triangle o x y R$ mutant as compared with wild type, which caused the induced fold change of soxS following paraquat treatment to be lower in the $\Delta o x y R$ mutant than in the wild type. The higher basal levels of soxS in the $\Delta o x y R$ mutant may be due to an increase in exogenous peroxide stress due to lack of OxyR. The SoxR/S system can also be stimulated by peroxide stress to some capacity (Manchado et al. 2000). In support of this, we also observed a 6.6-fold induction of soxS in the oxyR mutant following $\mathrm{H}_{2} \mathrm{O}_{2}$ treatment, which was not observed in the wild type. This, again, supports our speculation that the SoxR/S system may be stimulated in response to the accumulation of endogenous peroxides due to the lack of a functioning OxyR system.

\section{The OxyR and the SoxR/S regulatory systems contribute to virulence at different phases of host infection.}

Based on the method of inoculation used, it is possible to isolate the water-soaked lesion phase of Stewart's wilt from the wilting symptoms. When the whorls of seedlings are inoculated, the plants are not wounded and the pathogen does not enter the xylem. Therefore, the whorl inoculation method specifically tests the ability of the bacterium to colonize and cause water-

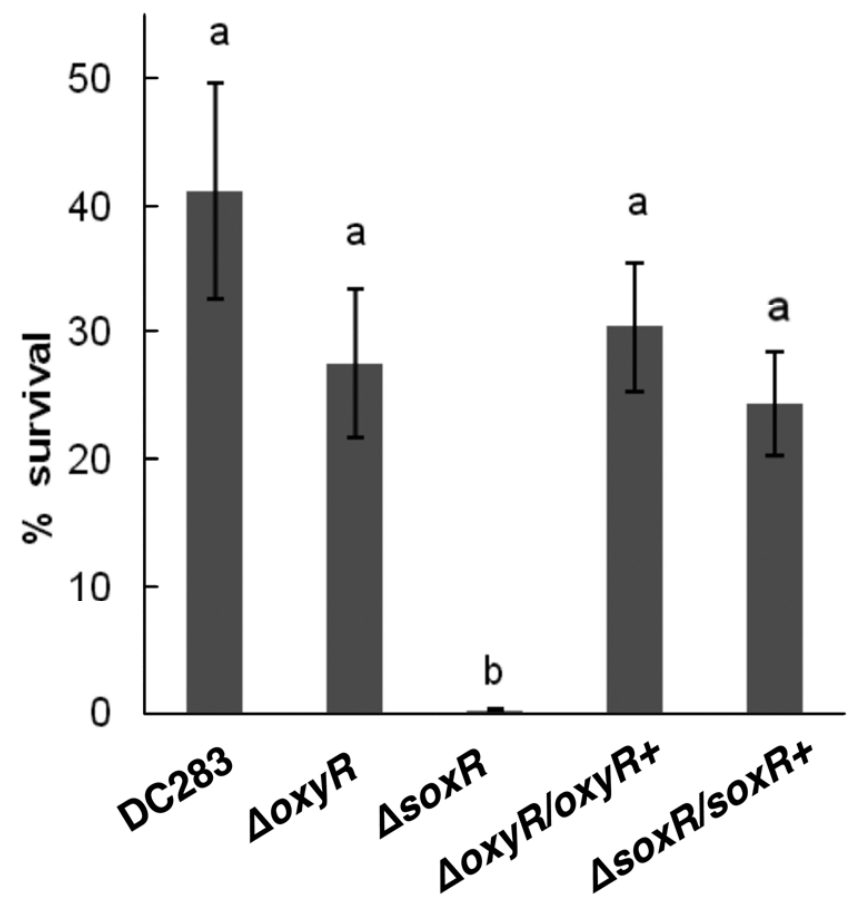

Fig. 3. $\Delta \operatorname{sox} R$ is more sensitive to paraquat. Strains were grown overnight in Luria Bertani (LB) medium and were diluted to an optical density at $600 \mathrm{~nm}=0.1 \mathrm{in} 2 \mathrm{ml}$ of fresh LB. Paraquat $(100 \mu \mathrm{M})$ was added to treated samples, and cells were grown for $3 \mathrm{~h}$ at $28^{\circ} \mathrm{C}$, while shaking at $180 \mathrm{rpm}$. Aliquots were diluted in $1 \times$ phosphate buffered saline and were plated on nutrient agar containing nalidixic acid. Colonies were counted after $48 \mathrm{~h}$ of incubation at $28^{\circ} \mathrm{C}$. The graph represents three biological replications with three technical replicates each. Experiments were repeated independently at least three times with similar results. Error bars = standard error of the mean. Bars labeled with different letters are significantly different based on a Student's $t$-test $(P \leq 0.02)$. soaked lesion development in the apoplastic space and does not assess wilting, which requires entry into the xylem. At 3 days postinoculation, on average, $40 \%$ of the $\Delta s o x R$-inoculated plants developed lesions as compared with $93 \%$ of the wild type-inoculated plants, indicating that the $\Delta$ soxR mutant was significantly compromised in the ability to cause watersoaked lesions (Fig. 5). Interestingly, 3 days postinoculation, the $\Delta \operatorname{sox} R$ mutant did not colonize the apoplast as well as the wild type, indicating a fitness defect, likely due to a deficient SoxR-dependent oxidative stress response (Fig. 6A, left). Plants inoculated with $\triangle o x y R$ using the whorl-inoculation technique developed water-soaked lesions similar to wild type-inoculated plants and colonized the plants to wild-type levels, indicating that deletion of $\operatorname{oxy} R$ has little consequence on lesion development or colonization of the apoplast (Figs. 5 and 6A, right). Plants inoculated with $1 \times$ PBS-T (phosphate buffered saline buffer containing $0.2 \%$ Tween 20 ) served as negative
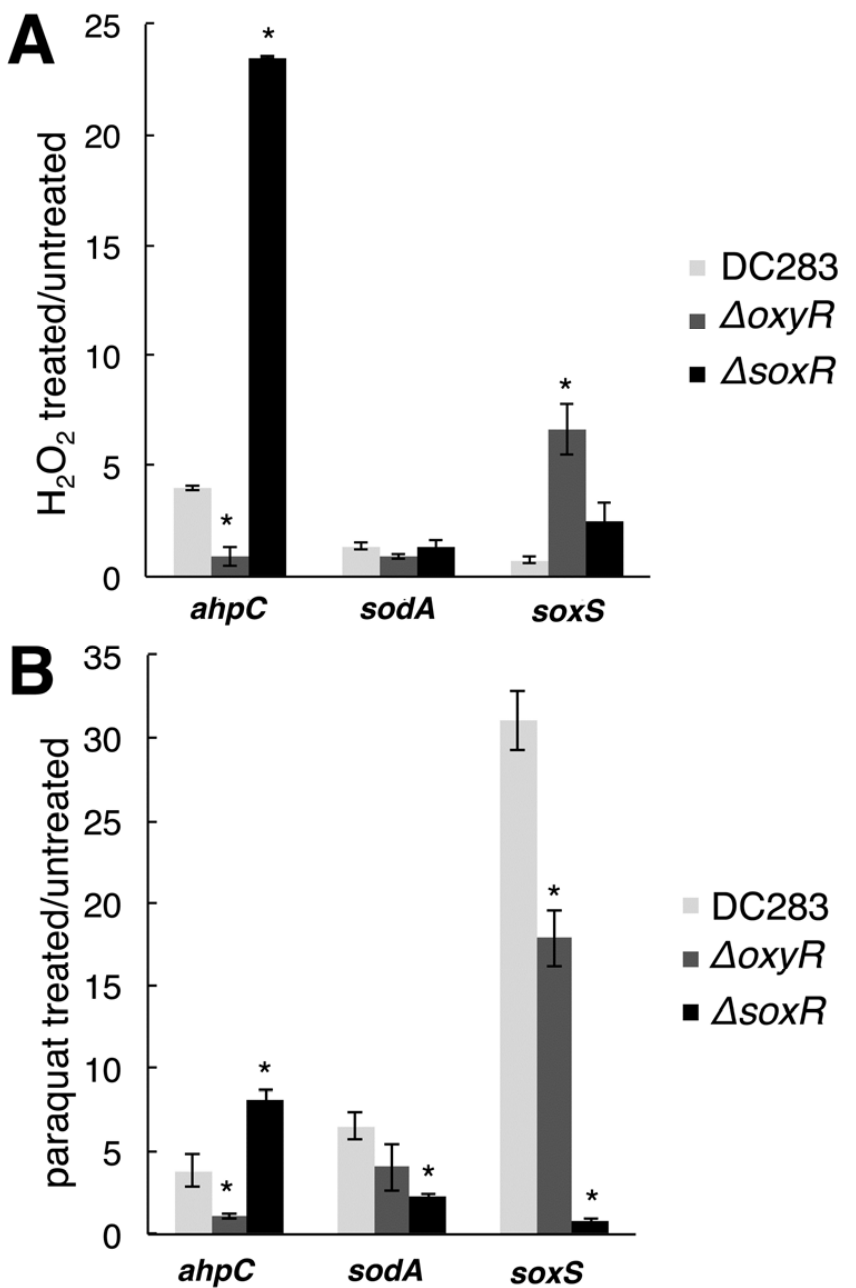

Fig. 4. OxyR and SoxR regulate expression of reactive oxygen species detoxification enzymes. Gene expression levels of $\operatorname{ahpC}$, $\operatorname{sodA}$, and $\operatorname{soxS}$ were quantified in response to treatment with either $\mathbf{A}, \mathrm{H}_{2} \mathrm{O}_{2}(0.1 \%$ final concentration) or $\mathbf{B}$, paraquat $(0.2 \mu \mathrm{g} / \mathrm{ml}$ final concentration). Cells were grown to mid-log phase (optical density at $600 \mathrm{~nm}=0.5$ ) in $\mathrm{AB}$ minimal medium, total RNA was harvested and was used to create first-strand cDNA by reverse transcription for use as a template for quantitative polymerase chain raction (qPCR). The quantitative gene expression level was normalized to two reference genes, ffh and proC. The qPCR data was analyzed using CFX Manager software (Bio-Rad Laboratories, Hercules, CA, U.S.A.) and was represented as mean normalized expression level compared with reference gene expression level. Asterisks (*) represent samples that are significantly different than the wild-type level of induction, based on the $95 \%$ confidence interval. 
controls and did not develop any Stewart's wilt symptoms. These differences were statistically significant, based on a Student's $t$-test using $P \leq 0.02$.

We also tested the virulence of $\Delta \operatorname{sox} R$ and $\Delta o x y R$, using the scratch-inoculation technique, which creates wounds using a syringe needle; the inoculum is then deposited in the wound, allowing bacteria to enter the plant and colonize the xylem and the apopolast. This method is designed to mimic the natural infection process facilitated by the corn flea beetle and allows assessment of the ability to cause the wilting that follows watersoaked lesion formation in young seedlings. At 6 days postinoculation, we monitored wilting symptoms and observed that the majority $(75 \%)$ of wild type-inoculated plants were wilting, whereas only $17 \%$ of the $\Delta o x y R$-inoculated plants showed wilting symptoms (Fig. 7). Interestingly, the $\Delta o x y R$ mutant colonized the plant to similar levels as wild-type $P$. stewartii (Fig. $6 \mathrm{~B}$, right). The $\Delta s o x R$ mutant caused a similar level of wilting as wild-type $P$. stewartii and colonized the scratch-inoculated plants to wild-type levels (Figs. 6B, left, and 7). Plants inoculated with $1 \times$ PBS-T served as negative controls and did not develop any Stewart's wilt symptoms. These differences were statistically significant, based on a Student's $t$-test using $P \leq$ 0.02 . These data indicate that the SoxR/S and OxyR regulatory systems are both required for full virulence of $P$. stewartii but during different phases of the infection cycle (i.e., water-soaking and wilting).

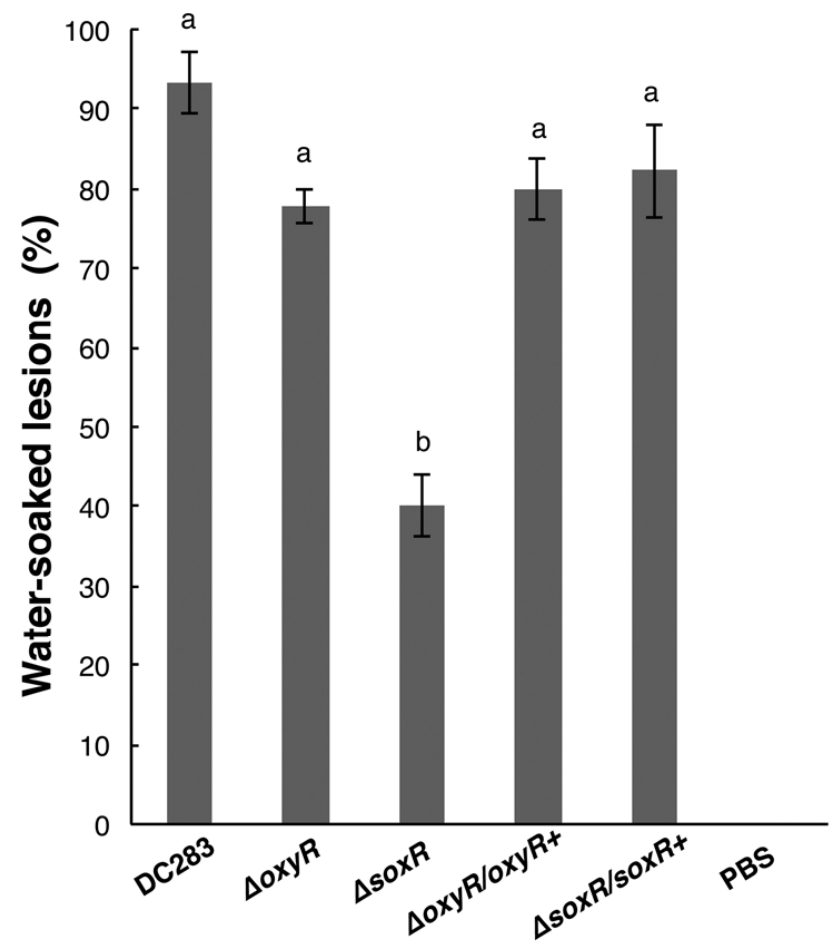

Fig. 5. $\Delta \operatorname{soxR}$ is deficient in water-soaked lesion formation. Whorl inoculations were performed on 10-day-old seedlings of a susceptible sweet corn variety (Zea mays var. Jubilee). Seedlings were inoculated with a bacterial suspension containing $1 \times 10^{7}$ cells $/ \mathrm{ml}$ resuspended in $1 \times$ phosphate buffered saline (PBS) containing $0.2 \%$ Tween $20(1 \times$ PBS-T). The inoculum was placed into the whorl of the seedling. At 3 days postinoculation, the numbers of plants exhibiting water-soaked lesions were quantified. Three biological replicates with five technical replicates each were tested in three separate trials (45 plants total). The results were expressed as the percent symptomatic plants. Seedlings inoculated with wild-type DC283 served as positive controls and seedlings inoculated with $1 \times$ PBS-T buffer alone served as negative controls. Error bars = standard error of the mean. Bars labeled with different letters are significantly different based on a Student's $t$-test $(P \leq 0.02)$.
A mutation in oxyR causes a decrease in EPS production.

The $\Delta o x y R$ mutant colonized scratch-inoculated plants to wild-type levels but caused less wilting, which prompted us to determine if OxyR may be controlling specific virulence factors relevant to xylem colonization, such as EPS production. EPS production is a known virulence factor for $P$. stewartii, and the wilting associated with Stewart's wilt is attributed to the blockage of xylem elements by EPS (Braun 1982). Qualitative measurements of EPS production indicate that the $\triangle o x y R$ mutant produces less EPS on EPS-inducing solid medium (nutrient agar supplemented with $0.4 \%$ glucose) (Fig. 8A). In addition, quantitative analysis performed in EPS-inducing broth (AB minimal medium [Clark 1967] supplemented with $0.4 \%$ glucose) further demonstrates that the $\Delta o x y R$ mutant produces less EPS per cell as compared with the wild type (Fig. $8 \mathrm{~B})$. Growth curves indicate that the $\Delta o x y R$ mutant grows similarly to wild-type $P$. stewartii (data not shown). The $\Delta$ soxR mutant produced as much EPS as the wild type under the same conditions, indicating that SoxR does not play a role in regulating EPS production. This suggests that the reduction in wilt symptom development observed for $\Delta o x y R$ is due, at least in part, to reduced EPS production, despite its ability to colonize the plant to wild-type levels.

\section{DISCUSSION}

Thus far, a carotenoid pigment has been identified as part of the antioxidant arsenal that $P$. stewartii uses to combat oxidative stress, but otherwise there is little information about how $P$. stewartii responds to the oxidative environment it encoun-
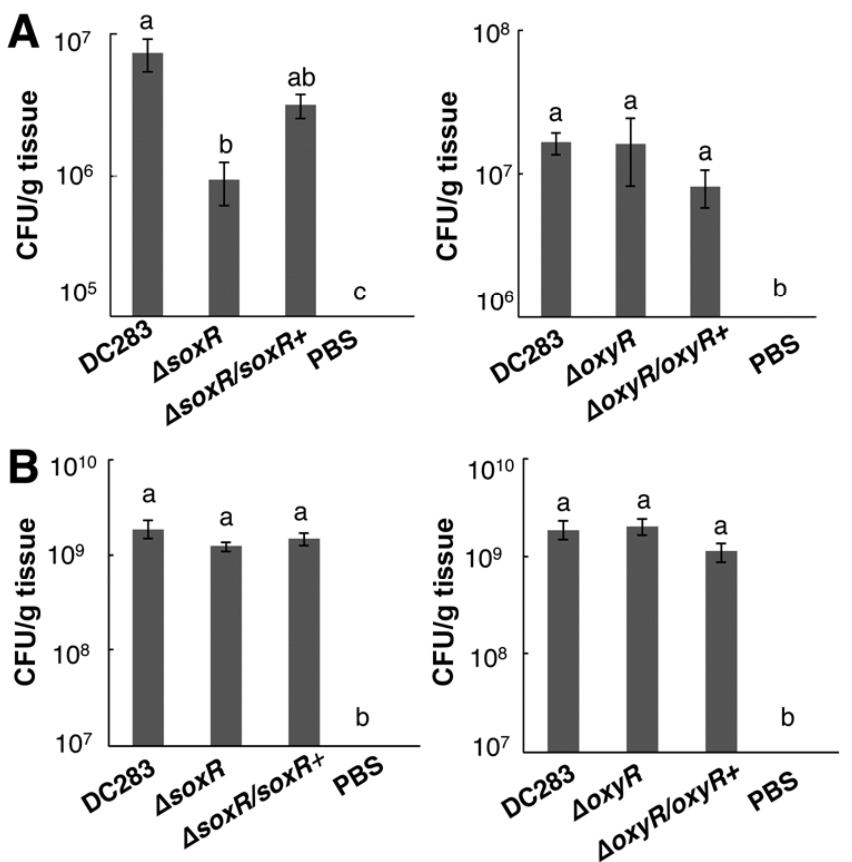

Fig. 6. Bacterial colonization in planta. The initial leaf from each inoculated plant was harvested from $\mathbf{A}$, whorl-inoculated plants or $\mathbf{B}$, scratchinoculated plants. Leaf tissue was individually weighed and surface-sterilized and was ground to a slurry in $2 \mathrm{ml}$ of $1 \times$ phosphate buffered saline (PBS). Serial dilutions of the plant slurry in $1 \times$ PBS were plated for viable cell counts. Colonies were counted after $48 \mathrm{~h}$ of incubation at $28^{\circ} \mathrm{C}$. Bacterial populations were quantified as CFU per gram of fresh tissue. Results shown are the average of 18 replicates. The mean CFU per gram for each strain was compared using a Kruskal-Wallis analysis of variance test at confidence level $P \leq 0.05$, followed by pairwise comparison using a Mann-Whitney nonparametric hypothesis test $(P \leq 0.05)$. Different letters indicate significant difference based on these tests. Error bars = standard error of the mean. 
ters in the plant (Mohammadi et al. 2012). In susceptible sweet corn, $P$. stewartii colonizes both the apoplast and the xylem to high population numbers $\left(>10^{8} \mathrm{CFU}\right.$ per gram of tissue). WtsE, a type III effector (Ham et al. 2006), and a cytolytic RTX-like toxin (M. C. Roper and S. B. von Bodman, unpublished data) have been implicated in causing the necrotic disease-associated cell death observed in water-soaked lesions. It is presumed that the bacterium uses plant cell lysis as a mechanism to obtain nutrients from the plant leaf tissue, but as a consequence, $P$. stewartii must cope with the ROS that are the result of plant cell leakage (van Doorn et al. 2011). Based on DAB and NBT staining, we demonstrate, here, that watersoaked lesions represent a highly oxidative environment and accumulate significant amounts of $\mathrm{H}_{2} \mathrm{O}_{2}$ and superoxide anions. Superoxide anions are charged and poorly diffusible across bacterial membranes. However, in some cases, plants can produce antimicrobial redox-cycling compounds, such as quinones, or signaling molecules, such as nitric oxide, which can diffuse across bacterial membranes and cause the production of intracellular superoxides (del Río et al., 2004; Søballe and Poole 1999). In contrast, $\mathrm{H}_{2} \mathrm{O}_{2}$ is uncharged and can diffuse across membranes, and thus, can directly enter the bacterial cell.

The SoxR/S system and members of its regulon, such as SodA, have been implicated in virulence for several different bacterial plant-pathogen systems, including Xanthomonas campestris and Dickeya dadantii (Mahavihakanont et al. 2012; Santos et al. 2001). Similarly, fewer plants inoculated with the $\triangle$ soxR mutant developed water-soaked lesions and bacteria were also recovered from significantly fewer of the $\Delta s o x R$ -

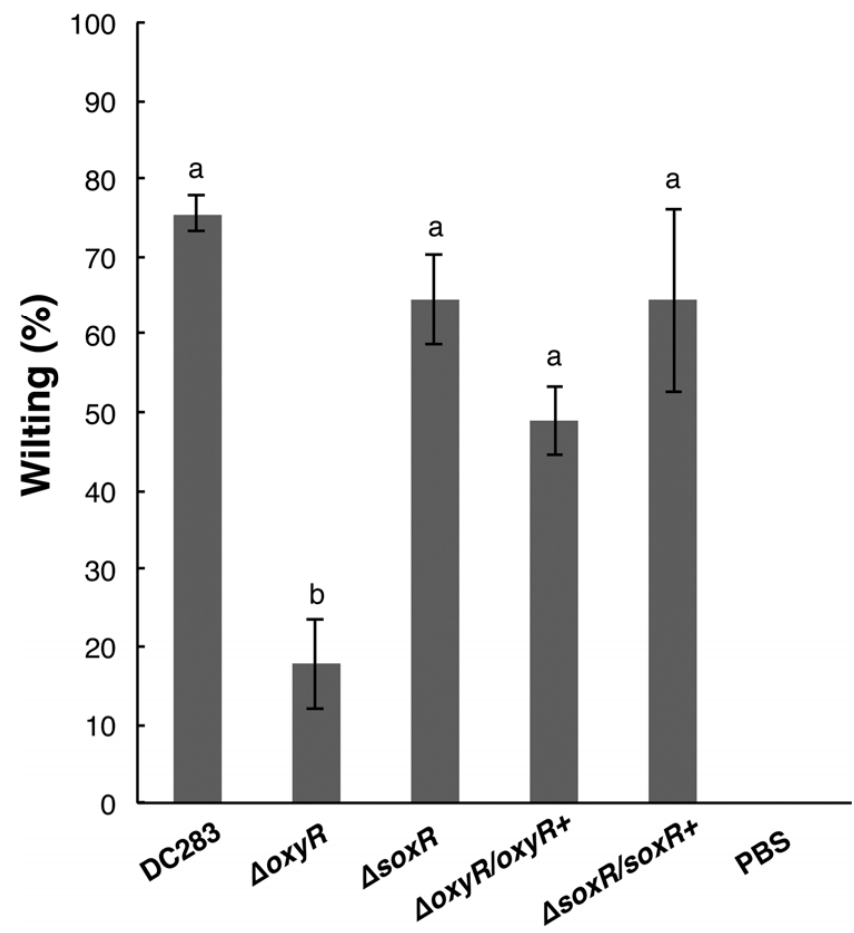

Fig. 7. $\triangle$ oxyR is deficient in the ability to cause wilting. Inoculum $(5 \mu \mathrm{l})$ containing $5 \times 107$ cells per milliliter in sterile $1 \times$ phosphate buffered saline (PBS) containing $0.2 \%$ Tween $20(1 \times$ PBS-T), was placed over a wound created by scratching the stem of a 10-day-old seedling with a sterile 20 gauge needle. Plants were observed for development of wilting symptoms 6 days after inoculation, and results were quantified as percent exhibiting wilting of the total number of plants. The graph represents the average of three independent experiments consisting of a total of 45 plants inoculated per strain. Seedlings inoculated with wild-type DC283 served as positive controls, and seedlings inoculated with $1 \times$ PBS-T buffer alone served as negative controls. Error bars $=$ standard error of the mean. Bars labeled with different letters are significantly different based on a Student's $t$-test $(P \leq 0.02)$. inoculated plants as compared with those inoculated with the wild-type parental strain. Here, we demonstrate that SoxR/S positively regulates soxS and $\operatorname{sod} A$ and a mutation in $\operatorname{soxR}$ negatively impacts the bacterium's ability to cope with exogenous superoxides and superoxide-generating compounds. Furthermore, the water-soaked lesions that result from $P$. stewartii invasion of the sweet corn apoplast contain superoxide anions, as determined by NBT staining. This indicates that coping with superoxide stress via the SoxR/S system is an important component of the colonization process for $P$. stewartii during early disease development. The SoxR/S regulon in E. coli also encodes a number of functions indirectly related to superoxide stress, such as replenishing the cellular NADPH pool and repairing cell damage (Pomposiello et al. 2001). It is possible that these other components of the SoxR/S regulon are also important for growth in the plant environment. We observed a significantly larger increase in $\operatorname{ahpC}$ expression in the $\Delta s o x R$ mutant in vitro compared with the wild type following peroxide treatment, suggesting that additional ROS detoxification functions, such as AhpC, could partially compensate for the lack of full induction of the SoxR/S system in the $\Delta$ soxR mutant. A similar physiological cross protection effect between the superoxide and peroxide stress responses occurs in Vibrio harveyi, in which treatment with the superoxide-generating compound menadione resulted in induction of peroxide-detoxifying enzymes, making the cells subsequently more resistant to peroxide stress (Vattanaviboon et al., 2003). However, despite this, the $\Delta$ soxR mutant was still compromised in virulence and colonization when inoculated into plants using the whorl inoculation technique, indicating that a fully functional SoxR/S sys-
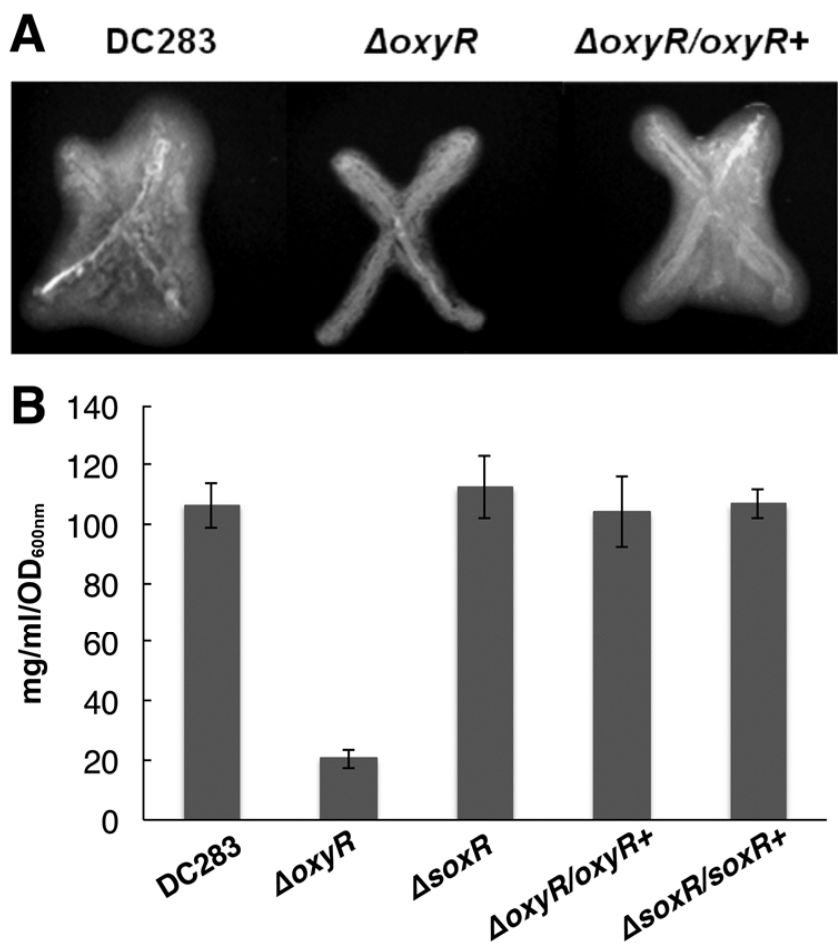

Fig. 8. $\triangle o x y R$ is deficient in exopolysaccharide (EPS) production. A, Qualitative EPS production on solid medium. Single colonies were struck onto nutrient agar plates containing $0.4 \%$ glucose in an $\mathrm{X}$ shape. Images were taken following overnight incubation at $28^{\circ} \mathrm{C}$. B, Quantitative analysis of EPS production in liquid medium. Cells were grown to late log phase (optical density at $600 \mathrm{~nm}\left[\mathrm{OD}_{600 \mathrm{~nm}}\right]=0.7$ ) in $\mathrm{AB}$ minimal medium containing $0.4 \%$ glucose. Following removal of cells by centrifugation, EPS was precipitated with three volumes of ethanol and was quantified using a phenol-sulfuric acid colorimetric assay. The graph represents the mean of nine samples \pm standard error of the mean. 
tem is required for colonization of the apopolast. Interestingly, $\triangle o x y R$ was capable of inducing the same level of water-soaked lesion formation as the wild-type parent, indicating that OxyR does not play a large role in regulating factors associated with the water-soaking phase of Stewart's wilt development. Similarly, Miguel and associates (2000) observed that an $\operatorname{oxy} R \mathrm{mu}-$ tant of $D$. dadantii was not compromised in virulence when infiltrated into tobacco leaves (Miguel et al. 2000). Thus, it appears that detoxification of $\mathrm{H}_{2} \mathrm{O}_{2}$ during colonization of the apoplast occurs through an OxyR-independent mechanism.

During $P$. stewartii host infection, the pathogen colonizes the plant systemically by entering and moving throughout the xylem network. Hydrogen peroxide levels of at least $10 \mu \mathrm{M}$ have been detected in the vascular tissue of $Z$. mays as a byproduct of normal xylem development processes (Barceló 1998). In some cases, OxyR can be activated by as little as $0.05 \mu \mathrm{M}$ hydrogen peroxide; thus, $P$. stewartii is likely exposed to $\mathrm{H}_{2} \mathrm{O}_{2}$ levels high enough to activate OxyR and, subsequently, its regulon in the xylem (Åslund et al. 1999). Lack of OxyR resulted in a significant decrease in the wilting symptoms that occur when $P$. stewartii colonizes the xylem tissue. Similarly, other xylem-dwelling pathogens, such as Ralstonia solanacearum and Xanthomonas campestris, also require OxyR for full virulence in the plant host and for tolerance to oxidative stress (Charoenlap et al. 2011; Flores-Cruz and Allen 2011). Surprisingly, we did not observe a decrease in overall $P$. stewartii bacterial numbers in plants inoculated with the $\Delta o x y R$ mutant, using either inoculation technique, indicating that the $\Delta o x y R$ mutant is sufficiently able to overcome any oxidative stress incurred despite its sensitivity to $\mathrm{H}_{2} \mathrm{O}_{2}$ in vitro. This could be due, in part, to compensation from other facets of the oxidative stress response, such as the SoxR/S system or the general stress response regulator RpoS, whose regulon includes genes involved in protection against oxidative stress, particularly during stationary phase (Gort et al. 1999; Patten et al. 2004). Indeed, in vitro, we observed a small but statistically significant induction of soxS in $\Delta o x y R$ following peroxide treatment, which did not occur in the wild type. Furthermore, the SoxR/S regulon can be induced at low levels by peroxide stress (Manchado et al. 2000), and it is possible that the lack of OxyR results in an increase in endogenous peroxide stress that, in turn, activates the SoxR/S system to some extent. However, it is important to note that bacterial isolations were performed on whole-leaf tissue, making it impossible to determine what percentage of the bacteria were present in the apoplast versus the xylem at the time of tissue harvest. Therefore, the reduction in wilting could be due to fewer bacteria inhabiting the xylem, which we were unable to ascertain based on the limitations of the isolation method.

OxyR was originally reported to be involved in the oxidative stress response but has since been implicated in the regulation of specific virulence factors, such as Ag43 in E. coli and fimbriae in Serratia marcescens (Henderson and Owen 1999; Shanks et al. 2007). The significant decrease in the elicitation of wilting by the $\Delta o x y R$ mutant prompted us to investigate if OxyR might be controlling expression of specific virulence factors that are relevant to xylem colonization and that ultimately lead to the wilting symptoms. EPS is a large macromolecule that causes vascular blockage in other bacterial wilt pathosystems (Leigh and Coplin 1992). It is presumed that production of EPS similarly leads to clogging of the xylem and blockage of water flow in the $P$. stewartii system (Braun 1982). EPS production is tightly correlated with $P$. stewartii virulence and mutants that produce less EPS are either nonpathogenic or deficient in their ability to cause wilting (Coplin et al. 1986; Von Bodman et al. 1998). Moreover, EPS production is a distinguishing feature of a biofilm and serves as a structural scaffold that aids in maintenance of biofilm architecture. Proper biofilm formation is absolutely necessary for systemic colonization of the xylem for $P$. stewartii (Koutsoudis et al. 2006). We found that EPS production was markedly reduced in the $\Delta o x y R$ mutant, which likely explains why $\Delta o x y R$-inoculated plants exhibit significantly less wilting despite quantitatively colonizing plants to wild-type numbers. Because of its significant reduction in EPS production, we speculate that the $\triangle o x y R$ mutant is likely deficient in forming the matrix-encased biofilms that are typical of $P$. stewartii colonization of the xylem that leads to vascular blockage associated with the wilting symptom. Indeed, in other systems, OxyR has been implicated in biofilm-related phenotypes, such as autoaggregation (Honma et al. 2009; Schembri et al. 2003) initial attachment to surfaces (Schembri et al. 2003), fimbrial gene expression (Shanks et al. 2007), and adhesion to host cells (Hennequin and Forestier 2009). There is one recent report linking OxyR to capsular polysaccharide production in S. enterica but, otherwise, its role in regulation of capsular polysaccharide is unclear (Pickard et al. 2013). We hypothesize that OxyR may be an important node in the regulatory circuit that controls EPS production and, hence, biofilm formation and proper spatiotemporal colonization of the xylem for $P$. stewartii. ROS sensed by OxyR may be an important environmental cue that signals entry into and maintenance of the biofilm state within the plant. The exact mechanism by which this occurs is unclear but warrants further investigation.

Another important source of ROS in plants is the oxidative burst. This important component of the host defense response includes the production of large amounts of superoxide anions and $\mathrm{H}_{2} \mathrm{O}_{2}$ in an attempt to defeat an invading pathogen (Bolwell et al. 2002). This process consists of two different phases: a smaller, nonspecific burst that is present in both compatible and incompatible interactions and a larger burst of ROS that is produced if the plant is resistant to the pathogen. The oxidative burst occurs immediately upon exposure to the pathogen, with ROS accumulation within the first hour (Lamb and Dixon 1997). DAB and NBT staining of inoculated leaf tissue did not detect visible ROS production $1 \mathrm{~h}$ postinoculation, though the amount of ROS produced during the initial oxidative burst could be below the detection limit of the staining methods used in this study. During the compatible $P$. stewartii-sweet corn interaction, the bacteria quickly colonize the plant to high population levels, especially in young susceptible seedlings; therefore, the oxidative burst is likely efficiently suppressed and, therefore, ineffective at preventing pathogen ingress. Ham and associates (2009) proposed that P. stewartii does, in fact, suppress the host defense response via the type III effector protein WtsE.

Mutations in either of the major redox-sensitive transcription factors led to only a partial reduction in virulence, indicating that $P$. stewartii can utilize alternate mechanisms to deal with oxidative stress, depending on its location within the plant. Apart from plant colonization, there are likely other scenarios during the lifecycle of $P$. stewartii in which the bacterium would encounter an oxidative environment. Insects possess an innate immune system that includes the production of ROS, and it is a distinct possibility that oxidative stress defense mechanisms play a role in adaptation to the environment within the gut of the corn flea beetle (Nappi and Ottaviani 2000).

\section{MATERIALS AND METHODS}

\section{Strains and growth conditions.}

All relevant strains are listed in Table 1. The P. stewartii strains were grown on nutrient agar (Difco Laboratories, Detroit), Luria-Bertani (LB) broth (Difco Laboratories), or AB minimal medium (Clark 1967) at $28^{\circ} \mathrm{C}$ in the presence of 
nalidixic acid $(30 \mu \mathrm{g} / \mathrm{ml})$, kanamycin $(30 \mu \mathrm{g} / \mathrm{ml})$, or chloramphenicol $(35 \mu \mathrm{g} / \mathrm{ml})$, when needed. Escherichia coli strains were grown at $37^{\circ} \mathrm{C}$ in LB in the presence of kanamycin $(30 \mu \mathrm{g} / \mathrm{ml})$, ampicillin $(100 \mu \mathrm{g} / \mathrm{ml})$, or chloramphenicol $(35 \mu \mathrm{g} / \mathrm{ml})$, as needed. $E$. coli DH10B was used as a cloning host and $\mathrm{S} 17-1 \lambda$ served as a donor for conjugal transfer of RK-2-based plasmid constructs into $P$. stewartii.

\section{Standard DNA manipulations.}

Genomic DNA was extracted with a Dneasy DNA extraction kit (Qiagen, Valencia, CA, U.S.A.). Plasmid DNA was purified with a Zyppytm plasmid miniprep kit (Zymo Research Corporation, Irvine, CA, U.S.A.). DNA fragments were amplified using Takara Ex-Taq DNA polymerase (Takara Bio USA, Madison, WI, U.S.A.). Synthetic oligonucleotide primers were ordered from Integrated DNA Technologies (Coralville, IN, U.S.A.). Restriction enzymes were purchased from New England Biolabs (Ipswich, MA, U.S.A.) or Invitrogen, Inc. (Carlsbad, CA, U.S.A.).

\section{Mutant construction.}

The P. stewartii $\Delta o x y R$ and $\Delta$ soxR mutants were created using a previously described method that is based on Gateway technology (Life Technologies, Inc., Carlsbad, CA, U.S.A.) (Choi and Schweizer 2005). The $\Delta s o x R$ mutant was created using primer pairs soxRLFfwd/soxRLFfwd, soxRRFfwdkan/oxRRFrev, and pKD13fwd/pKD13rev that amplified the $5^{\prime}$ and $3^{\prime}$ flanking regions of soxR (GenBank accession number EHT98350) and the kanamycin resistance cassette derived from plasmid pKD13 (Datsenko and Wanner 2000), respectively. In a second round of polymerase chain reaction (PCR), the three PCR products generated from the first round were combined into one tube (without primers) and were assembled by PCR overlap extension, using optimized PCR conditions. Primer pair soxRLFfwd/soxRRFrev was added after three rounds of PCR, and then, the rest of the PCR reaction was carried out. The resulting PCR product was cloned into vector pCR8/GW/TOPO (Invitrogen), following the manufacturer's instructions, to create plasmid pLPB14. This plasmid was recombined with a Gateway-compatible suicide vector, pAUC40, created from plasmid pKNG101 and modified to contain attL/attR-specific recombination sites (Carlier et al. 2009), to create plasmid pLPB15. The mutagenesis construct was separately transformed into $E$. coli S17-1 $\lambda$ for conjugation with wild-type $P$. stewartii, and the merodiploid state was resolved by sucrose selection. Sucroseresistant colonies were selected for kanamycin resistance $\left(\operatorname{Kan}^{\mathrm{r}}\right)$ and streptomycin sensitivity (streptomycin resistance is carried on the pKNG101 plasmid), and double-crossover events were confirmed using PCR with two primer sets designed to amplify the flanking regions of the soxR gene and the $\operatorname{Kan}^{\mathrm{r}}$ marker. The resulting PCR products were sequenced, and BLAST was used to confirm that the targeted soxR deletion had occurred and was replaced with the $\operatorname{Kan}^{\mathrm{r}}$ marker.

The $\Delta o x y R$ mutant was similarly created. Briefly, the $5^{\prime}$ and $3^{\prime}$ flanking regions of oxyR (GenBank accession number EHT98951) and the Kan cassette (from pKD13) (Datsenko and Wanner 2000) were amplified, using primer pairs oxyRFwdUp-GW/oxyR-UpR-Kan, oxyR-DnF-Kan/oxyRRevDn-GW, and pKD13fwd/pKD13rev, respectively. DC283 genomic DNA was used as template for amplification of the flanking regions of the oxyR open reading frame (ORF), using optimized PCR conditions. In a second round of PCR, the three PCR products generated from the first round were combined into one tube (without primers) and were assembled by PCR overlap extension using optimized PCR conditions. Primer pair GWattBl/ GWattB2 was added after three rounds of PCR, and then, the rest of the PCR reaction was carried out. The assembled PCR product containing attP recombination sites was then recombined into the pDONR/Zeo vector (Invitrogen) to create pMCR20. pMCR20 was linearized with AatII and was used to recombine into pAUC40 to create pMCR33. pMCR33 was introduced into $P$. stewartii DC283 by conjugation, and transconjugants were selected on LB medium containing Kan at 30 $\mu \mathrm{g} / \mathrm{ml}$. The mutagenesis construct was separately transformed into $E$. coli $\mathrm{S} 17-1 \lambda$ for conjugation with wild-type $P$. stewartii, and the merodiploid state was resolved by sucrose selection.

Table 1. Bacterial strains and plasmids

\begin{tabular}{|c|c|c|}
\hline Strain or plasmid & Relevant genotypes $^{\mathbf{a}}$ & Source or reference \\
\hline \multicolumn{3}{|c|}{ Pantoea stewartii subsp. stewartii } \\
\hline DC283 & Wild type, $\mathrm{Nal}^{\mathrm{r}}$ & Coplin et al. 1986 \\
\hline$\Delta o x y R$ LB003 & $\mathrm{Nal}^{\mathrm{r}}$, knockout in $\operatorname{oxy} R$ & This study \\
\hline$\triangle$ soxR LB020 & $\mathrm{Nal}^{\mathrm{r}}$, knockout in $\operatorname{soxR}$ & This study \\
\hline$\Delta o x y R / o x y R+\mathrm{LB} 037$ & $\begin{array}{l}\mathrm{Cm}^{\mathrm{r}}, \mathrm{Nal}^{\mathrm{r}} \text {, knockout in } \operatorname{oxy} R \text { complemented by chromosomal integration of wild-type } \\
\text { oxy } R \text { into intergenic region downstream of } \operatorname{glm} S\end{array}$ & This study \\
\hline$\Delta \operatorname{sox} R / \operatorname{sox} R+\mathrm{LB} 040$ & $\begin{array}{l}\mathrm{Cm}^{\mathrm{r}}, \mathrm{Nal}^{\mathrm{r}} \text {, knockout in soxR complemented by chromosomal integration of wild-type } \\
\text { soxR into intergenic region downstream of } \operatorname{glm} S\end{array}$ & This study \\
\hline \multicolumn{3}{|l|}{ Escherichia coli } \\
\hline DH10B & $\begin{array}{l}\text { F-endA1 recA1 galE15 galK16 nupG rpsL lacX74 } 80 l a c \text { Z M15 araD139 ara,leu } 7697 \\
\text { mcrA mrr-hsdR MS-mcrBC- }\end{array}$ & Invitrogen \\
\hline S17-1pir+ & $\mathrm{RP} 4, \mathrm{Mob}+, \mathrm{Sm}^{\mathrm{r}}$ & Simon et al. 1983 \\
\hline EC100pir+ & $\begin{array}{l}\text { F mcrA mrr-hsdRMS-mcrBC, 80dlacZ, M15 lacX74, recA1, endAlaraD139, ara, leu } \\
7697 \text { galU galK-rpsL nupG pir+DHFR }\end{array}$ & Epicentre \\
\hline \multicolumn{3}{|l|}{ Plasmids } \\
\hline pUC18R6K-mini-Tn7-cat & $\mathrm{Cm}^{\mathrm{r}}, \mathrm{amp}^{\mathrm{r}}$ & Choi et al. 2005 \\
\hline pAUC40 & $\mathrm{Cm}^{\mathrm{r}}, \mathrm{Sm}^{\mathrm{r}}$ & Carlier et al. 2009 \\
\hline pFLP2 & $\mathrm{sacB}+$, FLP recombinase, $A p^{r}$ & Kaniga et al. 1991 \\
\hline pKD13 & $\mathrm{Kan}^{\mathrm{r}}$ & Datsenko and Wanner 2000 \\
\hline pCR8/GW/TOPO & Cloning vector, $\mathrm{Sp}^{\mathrm{r}}$ & Invitrogen \\
\hline pDONR/Zeo & Cloning vector, Zeor, & Invitrogen \\
\hline pMCR20 & oxyR::kan cloned into pDONR/Zeo, $\mathrm{Kan}^{\mathrm{r}}, \mathrm{Zeo}^{\mathrm{r}}$ & This study \\
\hline pMCR33 & oxyR::kan cloned into pAUC40 $\mathrm{Sm}^{\mathrm{r}}, \mathrm{Kan}^{\mathrm{r}}$ & This study \\
\hline pLPB14 & soxR:: cloned into pCR8/GW/TOPO, $\mathrm{Sp}^{\mathrm{r}}, \mathrm{Kan}^{\mathrm{r}}$ & This study \\
\hline pLPB15 & soxR::kan cloned into pAUC40, $\mathrm{Sm}^{\mathrm{r}}, \mathrm{Kan}^{\mathrm{r}}$ & This study \\
\hline pLPB25 & oxyR cloned into pUC18R6K-mini-Tn7-cat, $\mathrm{Cm}^{\mathrm{r}}, \mathrm{Ap}^{\mathrm{r}}$ & This study \\
\hline pLPB27 & soxR cloned into pUC18R6K-mini-Tn7-cat, $\mathrm{Cm}^{\mathrm{r}}, \mathrm{Ap}^{\mathrm{r}}$ & This study \\
\hline
\end{tabular}

${ }^{\mathrm{a}} \mathrm{Nal}^{\mathrm{r}}, \mathrm{Cm}^{\mathrm{r}}, \mathrm{Sm}^{\mathrm{r}}, \mathrm{Ap}^{\mathrm{r}}, \mathrm{Sp}^{\mathrm{r}}, \mathrm{Kan}^{\mathrm{r}}$, and $\mathrm{Zeo}^{\mathrm{r}}$ indicate resistance to nalidixic acid, chloramphenicol, streptomycin, ampicillin, spectinomycin, kanamycin, and zeocin. 
Sucrose-resistant colonies were selected for $\mathrm{Kan}^{\mathrm{r}}$, and doublecrossover events were confirmed using PCR, with two primer sets designed to amplify the flanking regions of the $\operatorname{oxy} R$ gene and the $\operatorname{Kan}^{\mathrm{r}}$ marker. The resulting PCR products were sequenced, and BLAST was used to confirm that the targeted oxyR deletion had occurred and was replaced with the $\mathrm{Kan}^{\mathrm{r}}$ marker.

For both mutants, the Kan cassette used for selection was excised by Flp recombinase carried on pFLP2, leaving an 85bp frt scar to create the unmarked strains LB003 ( $\Delta o x y R)$ and LB020 ( $\Delta$ soxR). The pFLP2 plasmid was cured by sucrose selection. All relevant primer sequences can be found in Table 2 .

All mutant strains were complemented by insertion of a wild-type copy of the respective gene into a neutral region of the chromosome, using a mini-Tn7 vector system developed by Choi and associates (2005). In brief, the $o x y R$ ORF, with an additional $200 \mathrm{bp}$ upstream that included the native promoter region, was amplified by PCR, using primer pair oxyRfwdBamHI/OxyRrevPstI and was cloned into the BamHI and PstI restriction sites of the pUC18R6K-mini-Tn7-cat vector (Choi et al. 2005) to create plasmid pLPB25. The soxR ORF, with an additional $200 \mathrm{bp}$ upstream that included the native promoter, was amplified by PCR, using primer pair soxRfwdEcoRI/ soxRrevSmaI and was cloned into the EcoRI and SmaI restriction sites of the pUC18R6K-mini-Tn7-cat vector to create plasmid pLPB27. The pLPB25 and pLPB27 complementation constructs were transformed into $E$. coli $\mathrm{S} 17-1 \lambda$, and subsequently, conjugally transferred either into strain LB003 or LB020. The Tn7 constructs were expected to integrate into a single conserved chromosomal location in a neutral, intergenic region downstream of the $\operatorname{glm} S$ gene, as demonstrated in a number of bacterial species (Choi et al. 2005). Correct insertion into this site was confirmed by DNA sequencing of the glmS locus and downstream region.

\section{Detection of hydrogen peroxide and superoxide in corn leaves.}

At 3 days postinoculation, corn leaves were harvested from seedlings that had been inoculated with wild-type DC283, using the whorl-inoculation method as described below. Staining for the presence of hydrogen peroxide in the harvested plant tissue was performed using $\mathrm{DAB}$ and a protocol modified from Ramel and associates (2009). Briefly, leaves were submerged in staining solution, which was freshly prepared by dissolving DAB (Sigma-Aldrich) in $\mathrm{diH}_{2} \mathrm{O}$ at a concentration of 1.25 $\mathrm{mg} / \mathrm{ml}$ ( $\mathrm{pH} 3.8$ ). Leaves were left in the staining solution overnight on a rotary shaker. Following this, chlorophyll was removed using a solution of acetic acid, glycerol, and ethanol (1:1:3 ratio) and was held in a boiling water bath for $10 \mathrm{~min}$.
The leaves were stored in glycerol and ethanol (1:4 ratio) until photos were taken. Similarly infected corn leaves were used for superoxide anion detection, using a previously described and modified protocol (Ramel et al. 2009). Leaves were stained overnight on a rotary shaker in $3.5 \mathrm{mg}$ of NBT per milliliter (Sigma-Aldrich) and were dissolved in $10 \mathrm{mM}$ potassium phosphate containing $10 \mathrm{mM}$ sodium azide. Chlorophyll was removed using the same procedure as described for the DAB staining. Leaves harvested from mock-inoculated plants served as negative controls.

\section{Hydrogen peroxide and paraquat sensitivity assays.}

Hydrogen peroxide sensitivity assay. All strains were grown to mid-log phase (optical density at $600 \mathrm{~nm}\left[\mathrm{OD}_{600}\right]=0.5$ ) in LB medium. This cell suspension $(300 \mu \mathrm{l})$ was mixed with 3 $\mathrm{ml}$ of $0.8 \%$ nutrient top agar and overlaid on nutrient agar containing nalidixic acid $(30 \mu \mathrm{g} / \mathrm{ml})$. A Whatman paper disk containing $10 \mu \mathrm{l}$ of $100 \mathrm{mM} \mathrm{H} \mathrm{O}_{2}$ was placed in the center of the plate. Zones of growth inhibition surrounding the $\mathrm{H}_{2} \mathrm{O}_{2}$-treated disk were measured after $24 \mathrm{~h}$ of incubation at $28^{\circ} \mathrm{C}$.

Paraquat sensitivity assay. All strains were grown overnight in $\mathrm{LB}$ medium and were diluted to $\mathrm{OD}_{600}=0.1 \mathrm{in} 2 \mathrm{ml}$ of fresh LB. Paraquat $(100 \mu \mathrm{M})$ was added to treated samples, and cells were grown for $3 \mathrm{~h}$ at $28^{\circ} \mathrm{C}$ while shaking at $180 \mathrm{rpm}$. Aliquots were diluted in $1 \times$ PBS and were plated on nutrient agar containing nalidixic acid. Colonies were counted after $48 \mathrm{~h}$ of incubation at $28^{\circ} \mathrm{C}$. Experiments were performed on at least three biological replicates. Results are expressed as the mean of three independent experiments. Statistical analysis was performed using Minitab 16 software (Minitab, Inc., State College, PA, U.S.A.).

\section{Quantification of gene expression in cells treated with different sources of ROS.}

Cells were grown overnight in two $\mathrm{ml}$ of $\mathrm{AB}$ minimal medium, were diluted 1:20, and were grown to mid-log phase $\left(\mathrm{OD}_{600}=0.5\right)$ with the addition of $0.2 \%$ glucose and $0.05 \%$ yeast extract. Each culture was then separated into two parts, one treated with ROS, either $\mathrm{H}_{2} \mathrm{O}_{2}$ or paraquat (a superoxide anion generator), and one left untreated. For the $\mathrm{H}_{2} \mathrm{O}_{2}$-treated cells, freshly prepared $\mathrm{H}_{2} \mathrm{O}_{2}$ was added to the cultures at a final concentration of $0.1 \%$, and cultures were incubated for $10 \mathrm{~min}$ before total RNA was immediately extracted. For paraquat treatment, $2 \mu \mathrm{l}$ of freshly prepared paraquat (final concentration $0.2 \mu \mathrm{g} / \mathrm{ml}$ ) was added, and cultures were incubated for $1 \mathrm{~h}$ at $28^{\circ} \mathrm{C}$ while shaking at $180 \mathrm{rpm}$, prior to RNA extraction. RNA was immediately extracted following paraquat treatment. In all cases, total RNA was extracted using the hot phenol extraction method described by Jahn and associates (2008). Re-

Table 2. Primers used in this study

\begin{tabular}{lll}
\hline Primer & Sequence & Source or reference \\
\hline oxyRFwdUp-GW & TACAAAAAAGCAGGCTGATGCGCTGTATACCTGGCTG & This study \\
oxyR-UpR-Kan & GAAGCAGCTCCAGCCTACACAATCGCAGACCATCGGTGCTCCCGACCG & This study \\
oxyR-DnF-Kan & GGTCGACGGATCCCGGAATAATCCTGTTATAAGCCGGTACAC & This study \\
oxyRRevDn-GW & TACAAGAAAGCTGGGTCCTCAGCGCACCTGATCGAAG & This study \\
pKD13fwd & CGATTGTGTAGGCTGGAGCTGCTTC & This study \\
pKD13rev & AATTAATTCCGGGGATCCGTCGACC & This study \\
GWattB1 & GGGGACAAGTTGTACAAAAAAGCAGGCT & Choi and Schweizer 2005 \\
GWattB2 & GGGGACCACTTTGTACAAGAAAGCTGGGT & Choi and Schweizer 2005 \\
soxRLFfwd & CTGGCGACGCATGTAGTG & This study \\
soxRLFrevkan & GAAGCAGCTCCAGCCTACACAATCGCTGGCACTTTACCTCAAGTTAC & This study \\
soxRRFfwdkan & GGTCGACGGATCCCGGAATTAATTCTATACTGTCTGCATATTCATTC & This study \\
soxRRFrev & GATCATTTGCCTGTGGAC & This study \\
oxyRfwdBamHI & GCGCGCGGATCCGATGCGCTGTATACCTGG & This study \\
OxyRrevPstI & GCGCGGCTGCAGTTAAACCGC & This study \\
soxRfwdEcoRI & GCGCGAATTCTCTGTTTCGTTACGCTACGGA & This study \\
soxRrevSmaI & ATATCCCGGGTCACTTCACCTTGTGCAGAGAA & This study \\
\hline
\end{tabular}


moval of any residual genomic DNA was accomplished by treatment with TURBO DNase (Life technologies, Grand Island, NY, U.S.A.) according to the manufacturer's protocol. RNA purity and concentration were assessed by the absorbance ratio of 260/280 $\mathrm{nm}$ light, and RNA quality was analyzed by agarose gel electrophoresis. DNA-free RNA (500 ng) was used for cDNA synthesis using the iScript cDNA synthesis kit (Bio-Rad Laboratories, Hercules, CA, U.S.A.), according to the manufacturers' protocol. The level of gene expression between the different strains and under different conditions was compared by quantitative (q)PCR, using iQ SYBR Green supermix (Bio-Rad Laboratories). Genes monitored for expression changes were $\operatorname{ahpC}$ (GenBank accession number EHU00213), soxS (GenBank accession number EHT98349), and sodA (GenBank accession number EHT98761). Fluorescence detection was performed in a CFX96 real-time PCR detection instrument (Bio-Rad Laboratories). Primers for qPCR analysis were designed using Beacon Design software and were analyzed for optimal concentration and annealing temperature prior to use. Gene expression was normalized to two reference genes, ffh (GenBank accession number EHT99250) and proC (GenBank accession number EHU02233), chosen based on previous work (Takle et al. 2007) and compared for stability across treatment conditions. The qPCR data were analyzed using the CFX Manager software (Bio-Rad Laboratories) and were expressed as a fold gene expression change compared with untreated controls, plus or minus the standard error of the mean.

\section{In planta virulence assays.}

Virulence was assessed for all strains using two techniques, whorl inoculation (Ham et al. 2006) and scratch inoculation (Herrera et al. 2008). Whorl inoculations were performed on 10 -day-old seedlings of a susceptible sweet corn variety $(Z$. mays var. Jubilee). Seedlings were inoculated with a bacterial suspension of approximately $1 \times 10^{7}$ cells resuspended in $1 \times$ PBS-T (PBS buffer containing 0.2\% Tween 20). The inoculum was placed into the whorl of the seedling. Disease progression was assessed by a general Stewart's wilt disease rating system from 0 and 4 , in which $0=$ no symptoms, $1=$ a few lesions, 2 $=$ spreading lesions that coalesce, $3=$ severe lesions plus some wilt, and $4=$ severe wilting and death of the plant. At 3 days postinoculation, the number of plants showing water-soaked lesions was quantified. Plants inoculated via the whorl-inoculation method generally only developed lesions and scored a rating of 1 or 2 . The plants do not wilt because the bacteria primarily colonize the apoplastic space and do not enter the xylem, which requires wounding. At least three biological replicates of the bacterial strains were inoculated into five plants each for a total of fifteen plants per strain for each trial. Trials were repeated independently at least three times. Results were expressed as the percentage of symptomatic plants. Seedlings inoculated with wild-type DC283 served as positive controls, and seedlings mock-inoculated with $1 \times$ PBS-T buffer alone served as negative controls.

The scratch-inoculation method was designed to mimic the feeding behavior of the corn flea beetle (Herrera et al. 2008). Inoculum $(5 \mathrm{ml})$ containing $5 \times 10^{7}$ cell $/ \mathrm{ml}$ in sterile $1 \times \mathrm{PBS}$ $\mathrm{T}$ was placed over a wound created by scratching the stem of a 10-day-old seedling with a sterile 20-gauge syringe needle. Disease scores were assigned using the same rating system as above. Plants were observed for development of wilting symptoms (score of 3 or higher) 6 days postinoculation, and results were quantified as the percentage of the total number of plants inoculated that exhibited wilting. At least three biological replicates of the bacterial strains were inoculated into five plants each for a total of fifteen plants per strain for each trial. Trials were repeated independently at least three times. Results were expressed as the percentage of symptomatic plants. Seedlings inoculated with wild-type DC283 served as positive controls, and seedlings inoculated with $1 \times$ PBS-T buffer alone served as negative controls. For both virulence assays, statistical analyses were performed on the mean values for at least three independent experiments using Minitab 16 software (Minitab, Inc.).

\section{Quantification of bacterial populations in the plant.}

The initial leaf from each inoculated plant was harvested 6 days postinoculation. Leaf tissue was individually weighed and surface-sterilized using the following procedure. Leaves were soaked in $70 \%$ ethanol and, then, by $10 \%$ bleach for $30 \mathrm{~s}$ each, rinsing twice in sterile $\mathrm{diH}_{2} \mathrm{O}$ (30 s for each rinse). Following this, the leaf tissue was placed in a sterile plastic grinding bag (Agdia, Inc. Elkhart, IN, U.S.A.) with $2 \mathrm{ml}$ of sterile $1 \times$ PBS and was ground to a slurry. Serial dilutions of the plant slurry in $1 \times$ PBS were plated for viable cell counts. Colonies were counted after $48 \mathrm{~h}$ of incubation at $28^{\circ} \mathrm{C}$. Bacterial populations were quantified as $\mathrm{CFU}$ per gram of fresh tissue.

\section{EPS isolation and quantification.}

EPS was extracted from culture supernatants by ethanol precipitation. All strains were grown in $15 \mathrm{ml}$ of $\mathrm{AB}$ minimal medium with the addition of $0.4 \%$ glucose to late log phase $\left(\mathrm{OD}_{600}=0.7\right)$. Cells were removed by centrifugation, and EPS was precipitated with three volumes of $95 \%$ ethanol at $-80^{\circ} \mathrm{C}$ for $30 \mathrm{~min}$. EPS was then collected by centrifugation at 6,000 rpm for 20 min. EPS was washed twice with cold $70 \%$ ethanol and was resuspended in $1 \times \mathrm{PBS}$ at $37^{\circ} \mathrm{C}$. EPS was quantified using the phenol-sulfuric acid colorimetric assay described by Matsuko and associates (2005). Total EPS was normalized to starting cell density $\left(\mathrm{OD}_{600}\right)$.

\section{ACKNOWLEDGMENTS}

This work was supported by an award to M. C. Roper by the Regents of the University of California, Riverside and the Agricultural Experiment Station and College of Natural and Agricultural Sciences. Funding was also provided by the Hellman Fellowship Foundation in a fellowship awarded to M.C. Roper. This work was supported in part by the National Science Foundation through grant number 1053869 awarded to S. von Bodman. In addition, this material is based on work supported by the National Science Foundation while S. von Bodman was working at the Foundation. Any opinion, finding, and conclusions or recommendations expressed in this material are those of the author and do not necessarily reflect the views of the National Science Foundation. We thank C. S. Ingel and M. Daugherty for their assistance with statistical analysis.

\section{LITERATURE CITED}

Apel, K., and Hirt, H. 2004. Reactive oxygen species: Metabolism, oxidative stress, and signal transduction. Annu. Rev. Plant Biol. 55:373-399.

Åslund, F., Zheng, M., Beckwith, J., and Storz, G. 1999. Regulation of the OxyR transcription factor by hydrogen peroxide and the cellular thiolDisulfide status. Proc. Natl. Acad. Sci. U.S.A. 96:6161-6165.

Barceló, A. R. 1998. Hydrogen peroxide production is a general property of the lignifying xylem from vascular plants. Ann. Bot. 82:97-103.

Barceló, A. R., 2005. Xylem parenchyma cells deliver the $\mathrm{H}_{2} \mathrm{O}_{2}$ necessary for lignification in differentiating xylem vessels. Planta 220:747-756.

Bolwell, G. P., Bindschedler, L. V., Blee, K. A, Butt, V. S., Davies, D. R., Gardner, S. L., Gerrish, C. and Minibayeva, F. 2002. The apoplastic oxidative burst in response to biotic stress in plants: A three-component system. J. Exp. Bot. 53:1367-1376.

Braun, E. J. 1982. Ultrastructural investigation of resistant and susceptible maize inbreds infected with Erwinia stewartii. Phytopathology 72:159166.

Buchanan, B. B., Gruissem, W., and Jones, R. L. 2000. Responses to plant pathogens. Pages 1102-1156 in: Biochemistry and Molecular Biology of Plants. American Society of Plant Physiologists, Rockville, MD, U.S.A.

Cabiscol, E., Tamarit, J., and Ros, J. 2000. Oxidative stress in bacteria and protein damage by reactive oxygen species. Int. Microbiol. 3:3-8. 
Carlier, A. L., Burbank, L. P., and Von Bodman, S. B. 2009. Identification and characterization of three novel EsaI/EsaR quorum-sensing controlled stewartan exopolysaccharide biosynthetic genes in Pantoea stewartii ssp. stewartii. Mol. Microbiol.74:903-913.

Charoenlap, N., Buranajitpakorn, S., Duang-Nkern, J., Namchaiw, P., Vattanaviboon, P.,and Mongkolsuk, S. 2011. Evaluation of the virulence of Xanthomonas campestris pv. campestris mutant strains lacking functional genes in the OxyR Regulon. Curr. Microbiol. 63:232-237.

Choi, K-H., Gaynor, J. B., and White, K. G., Lopez, C., Bosio, C. M., Karkhoff-Schweizer, R. R., and Schweizer, H. P. 2005. A Tn7-based broad-range bacterial cloning and expression system. Nat. Meth. 2:443448

Choi, K. H., and Schweizer, H. P. 2005. An improved method for rapid generation of unmarked Pseudomonas aeruginosa deletion mutants. BMC Microbiol. 5:30.

Chou, J. H., Greenberg, J. T., and Demple, B. 1993. Posttranscriptional repression of Escherichia coli OmpF protein in response to redox stress: Positive control of the micF antisense RNA by the soxRS locus. J. Bacteriol.175:1026-1031

Christman, M. F., Morgan, R. W., Jacobson, F. S., and Ames, B. N. 1985 Positive contol of a regulon for defenses against oxidative stress and some heat-shock proteins in Salmonella typhimurium. Cell 41:753-762.

Claflin L, 1999. Compendium of Corn Diseases. American Phytopathological Society, St. Paul, MN, U.S.A.

Clark, J. D., and Maaloe, O. 1967. DNA replication and the cell division cycle in Escherichia coli. J. Mol. Biol. 23:99-112.

Coplin, D. L., Frederick, R. D., Majerczak, D. R., and Haas, E. S, 1986. Molecular cloning of virulence genes from Erwinia stewartii. J. Bacteriol. 168:619-623.

Datsenko, K. A., and Wanner, B. L. 2000. One-step inactivation of chromosomal genes in Escherichia coli K-12 using PCR products. Proc. Natl. Acad. Sci. U.S.A. 97:6640-6645.

Del Río, L. A., Corpas, J. F., and Barroso, J. B. 2004. Nitric oxide and nitric oxide synthase activity in plants. Phytochemistry 65:783-792.

Fang, F. C., Vazquez-Torres, A.,and Xu ,Y. 1997. The transcriptional regulator SoxS is required for resistance of Salmonella typhimurium to paraquat but not for virulence in mice. Infect. Immun.65:5371-5375.

Flores-Cruz, Z., and Allen, C. 2011. OxyR is necessary for the hydrogen peroxide stress response and full virulence in Ralstonia solanacearum. Appl. Environ. Microbiol. 7:6426-6432.

Gaudu, P., and Weiss, B.1996. SoxR, a [2Fe-2S] transcription factor, is active only in its oxidized form. Proc.Natl. Acad. Sci. U.S.A. 93:1009410098.

Glasner, J. D., Rusch, M., Liss, P., Plunkett, G., Cabot, E. L., Darling, A., Anderson, B. D., Infield-Harm, P., Gilson, M. C. and Perna, N. T. 2006. ASAP: A resource for annotating, curating, comparing and disseminating genomic data. Nucleic Acids Res. 34:41-45.

Gort, A. S., Ferber, D. M.,and Imlay, J. A. 1999. The regulation and role of the periplasmic copper, zinc superoxide dismutase of Escherichia coli. Mol. Microbiol. 32:179-191.

Greenberg, J. T., Monach ,P., Chou, J. H., Josephy, P. D., and Demple, B., 1990. Positive control of a global antioxidant defense regulon activated by superoxide-generating agents in Escherichia coli. Proc. Natl. Acad. Sci. U.S.A. 87:6181-6185.

Grellet-Bournonville, C. F., and Díaz-Ricci, J. C. 2011. Quantitative determination of superoxide in plant leaves using a modified NBT staining method. Phytochem. Anal. 22:268-271.

Gu, M., and Imlay, J. 2011. The SoxR response in Escherichia coli is directly activated by redox-cycling drugs rather than superoxide. Mol. Microbiol. 79:1136-1150.

Ham, J. H., Majerczak, D. R., Arroyo-Rodriquez, A. S., Mackey, D. M., and Coplin, D. L. 2006. WtsE, an AvrE-family effector protein from Pantoea stewartii subsp. stewartii, causes disease-associated cell death in corn and requires a chaperone protein for stability. Mol. PlantMicrobe Interact.19:1092-1102.

Henderson, I. R., and Owen, P. 1999. The major phase-variable outer membrane protein of Escherichia coli structurally resembles the immunoglobulin A1 protease class of exported protein and is regulated by a novel mechanism involving Dam and OxyR. J. Bacteriol. 181:21322141

Hennequin, C., and Forestier, C. 2009. OxyR, a LysR-type regulator involved in Klebsiella pneumoniae mucosal and abiotic colonization. Infect. Immun. 77:5449-5457.

Herrera, C. M., Koutsoudis, M. D., Wang, X., and Von Bodman, S. B. 2008. Pantoea stewartii subsp. stewartii exhibits surface motility, which is a critical aspect of Stewart's Wilt disease development on maize. Mol. Plant-Microbe Interact. 21:1359-1370.

Honma, K., Mishima, E., Inagaki, S., and Sharma, A. 2009. The OxyR homologue in Tannerella forsythia regulates expression of oxidative stress responses and biofilm formation. Microbiology 155:1912-1922.
Imlay, J. 2008. Cellular defenses against superoxide and hydrogen peroxide. Annu. Rev. Biochem. 77:755-776.

Jahn, C. E., Charkowski, A. O., and Willis, D. K. 2008. Evaluation of isolation methods and RNA integrity for bacterial RNA quantification. J. Microbiol. Methods 75:318-324.

Kaniga, K., Delor, I., and Cornelis, G. R. 1991. A wide-host-range suicide vector for improving reverse genetics in Gram-negative bacteria: Inactivation of the blaA gene of Yersinia enterocolitica. Gene 109:137-141.

Koutsoudis, M. D., Tsaltas, D., Minogue, T. D., and Von Bodman, S. B. 2006. Quorum-sensing regulation governs bacterial adhesion, biofilm development, and host colonization in Pantoea stewartii subsp. stewartii. Proc. Natl. Acad. Sci. U.S.A.103:5983-5988.

Kullik, I., Toledano, M. B., Tartaglia, L. A., and Storz, G. 1995. Mutational analysis of the redox-sensitive transcriptional regulator OxyR: Regions important for oxidation and transcriptional activation. J. Bacteriol. 177:1275-1284.

Lamb, C.,and Dixon, R. A. 1997. The oxidative burst in plant disease resistance. Annu. Rev. Plant Physiol. Plant Mol. Biol. 48:251-275.

Leigh, J. A., and Coplin, D. L. 1992. Exopolysaccharides in plant-bacterial interactions. Annu. Rev. Microbiol. 46:307-346.

Liochev, S. I., Benov, L., Touati, D., and Fridovich, I. 1999. Induction of the SoxRS regulon of Escherichia coli by superoxide. J. Biol. Chem. 274:9479-9481.

Mahavihakanont, A., Charoenlap, N., Namchaiw, P., Chattrakarn, S., Vattanaviboon, P., and Mongkonsuk, S. 2012. Novel roles of SoxR, a transcriptional regulator from Xanthomonas campestris, in sensing redoxcycling drugs and regulating a protective gene that have overall implications for bacterial stress physiology and virulence on a host plant. J. Bacteriol.194:209-217.

Manchado, M., Michán, C., and Pueyo, C. 2000. Hydrogen peroxide activates the SoxRS regulon in vivo. J. Bacteriol. 182:6842-6844.

Marchler-Bauer, A., Zheng, C., Chitsaz, F., Derbyshire, M. K., Geer, L.Y., Geer, R. C., Gonzales, N. R., Gwadz, M., Hurwitz, D. I., Lanczycki, C. J., Lu, F., Lu, S., Marchler, G. H., Song, J. S., Thanki, N., Yamashita, R. A., Zhang, D., and Bryant, S. H. 2013. CDD: Conserved domains and protein three-dimensional structure. Nucleic Acids Res. 41:D348-D52.

Matsuko, T., Minami, A., Iwasaki, N., Majima, T., Nishimura, S-I., and Lee, Y. C. 2005. Carbohydrate analysis by a phenol-sulfuric acid method in microplate format. Anal. Biochem. 339:69-72.

Miguel, E., Poza-Carrión, C., López-Solanilla, E., Aguilar, I., LlamaPalacios, A., García-Olmedo, F., and Rodríguez-Palenzuela, P. 2000. Evidence against a direct antimicrobial role of $\mathrm{H}_{2} \mathrm{O}_{2}$ in the infection of plants by Erwinia chrysanthemi. Mol.Plant-Microbe Interact. 13:421429.

Mohammadi, M., Burbank, L., and Roper, M. C. 2012. Biological role of pigment production for the bacterial phytopathogen Pantoea stewartii subsp stewartii. Appl. Environ. Microbiol. 78:6859-6865.

Mukhopadhyay, S., and Schellhorn, H. E. 1997. Identification and characterization of hydrogen peroxide-sensitive mutants of Escherichia coli: Genes that require OxyR for expression. J. Bacteriol. 179:330-338.

Nappi, A. J., and Ottaviani, E. 2000. Cytotoxicity and cytotoxic molecules in invertebrates. BioEssays 2:469-480.

Nunoshiba, T., Derojas-Walker, T., Tannenbaum, S.R., and Demple, B.1995. Roles of nitric oxide in inducible resistance of Escherichia coli to activated murine macrophages. Infect. Immun. 63:794-798.

Nunoshiba, T., Derojas-Walker, T., Wishnok, J. S., Tannenbaum, S. R., and Demple, B. 1993. Activation by nitric oxide of an oxidative-stress response that defends Escherichia coli against activated macrophages. Proc. Natl. Acad. Sci. U.S.A. 90:9993-9997.

Pataky, J. 2003. Stewart's wilt of corn. American Phytopathological Society, St. Paul, MN, U.S.A. doi: 10.1094/APSnetFeature-2003-0703. Published onlilne.

Patten, C. L., Kirchhof, M. G., Schertzberg, M. R., Morton, R. A., and Schellhorn, H. E. 2004. Microarray analysis of RpoS-mediated gene expression in Escherichia coli K-12. Mol. Genet. Genomics 272:580-591.

Pickard, D., Kingsley, R. A., Hale, C., Turner, K., Sivaraman, K., Wetter, M., Langridge, G., and Dougan, G. 2013. A genomewide mutagenesis screen identifies multiple genes contributing to Vi capsular expression in Salmonella enterica serovar Typhi. J. Bacteriol. 195:1320-1326.

Pomposiello, P. J., Bennik, M. H. J., and Demple, B. 2001. Genome-wide transcriptional profiling of the Escherichia coli responses to superoxide stress and sodium salicylate. J. Bacteriol. 183:3890-3902.

Pomposiello, P. J., and Demple, B. 2001. Redox-operated genetic switches: The SoxR and OxyR transcription factors. Trends Biotechnol. 19:109-114.

Pullan, S. T., Gidley, M. D., Jones, R. A., Barrett, J., Stevanin, T. M., Read, R. C., Green, J. and Poole, R. K. 2007. Nitric oxide in chemostatcultured Escherichia coli is sensed by Fnr and other global regulators: Unaltered methionine biosynthesis indicates lack of S-nitrosation. J. Bacteriol. 189:1845-1855. 
Ramel, F., Sulmon, C., Bogard, M., Couee, I., and Gouesbet, G. 2009. Differential patterns of reactive oxygen species and antioxidative mechanisms during atrazine injury and sucrose-induced tolerance in Arabidopsis thaliana plantlets. BMC Plant Biol. 9:28.

Roper, M. C. 2011. Pantoea stewartii subsp. stewartii: Lessons learned from an important xylem-dwelling pathogen of sweet corn. Mol. Plant Pathol. 12:628-637.

Santos, R., Franza, T., Laporte, M-L., Sauvage, C., Touati, D., and Expert, D. 2001. Essential role of superoxide dismutase on the pathogenicity of Erwinia chrysanthemi strain 3937. Mol. Plant-Microbe Interact. 14:758-767.

Schellhorn, H. E. 1994. Regulation of hydroperoxidase (catalase) expression in Escherichia coli. FEMS (Fed. Eur. Microbiol. Soc.) Microbiol. Lett. 131:113-119.

Schembri, M. A., Hjerrild, L., Gjermansen, M., and Klemm, P. 2003. Differential expression of the Escherichia coli autoaggregation factor antigen 43. J. Bacteriol. 185:2236-2242.

Seaver, L. C., and Imlay, J. A. 2001. Alkyl hydroperoxide reductase is the primary scavenger of endogenous hydrogen peroxide in Escherichia coli. J. Bacteriol. 183:7173-7181.

Shanks, R. M., Stella, N. A., and Kalivoda, E. J., Doe, M. R. O'Dee, D. M., Lathrop, K. L., Guo, F. L., and Nau, G. J. 2007. A Serratia marcescens OxyR homolog mediates surface attachment and biofilm formation. J. Bacteriol. 189:7262-7272.

Simon, R., Priefer, U., and Puhler, A., 1983. A broad host range mobilization system for in vivo genetic engineering: Transposon mutagenesis in gram negative bacteria. Nat. Biotechnol. 1:784-791.

Søballe, B., and Poole, R. K. 1999. Microbial ubiquinones: Multiple roles in respiration, gene regulation and oxidative stress management. Microbiology 145:1817-1830.

Storz, G., Tartaglia, L. A., Farr, S. B., and Ames, B. N. 1990. Bacterial defenses against oxidative stress. Trends Genet. 6:363-368.

Takle, G. W., Toth, I. K., and Brurberg, M. B. 2007. Evaluation of refer- ence genes for real-time RT-PCR expression studies in the plant pathogen Pectobacterium atrosepticum. BMC Plant Biol. 7:50.

Thordal-Christensen, H., Zhang, Z. G., Wei, Y. D., and Collinge, D. B. 1997. Subcellular localization of $\mathrm{H}_{2} \mathrm{O}_{2}$ in plants. $\mathrm{H}_{2} \mathrm{O}_{2}$ accumulation in papillae and hypersensitive response during the barley-powdery mildew interaction. Plant J. 11:1187-1194.

Tsaneva, I. R., and Weiss, B. 1990. soxR, a locus governing a superoxide response regulon in Escherichia coli K-12. J. Bacteriol. 172:4197-4205.

Van Doorn, W. G., Beers, E. P.,and Dangl, J. L., Franklin-Tong, V. E., Gallois, P., Hara-Nishimura, I., Jones, A. M., Kawai-Yamada, M., Lam, E., Mundy, J. Mur, L. A. J., Petersen, M., Smertenko, A., Taliansky, M., Van Breusegem, F., Wolpert, T., Woltering, E., Zhivotovsky, B., and Bozhkov, P. V. 2011. Morphological classification of plant cell deaths. Cell. Death. Differ. 18:1241-1246.

Vattanaviboon, P., Panmanee, W., and Mongkolsuk, S. 2003. Induction of peroxide and superoxide protective enzymes and physiological crossprotection against peroxide killing by a superoxide generator in Vibrio harveyi. FEMS (Fed. Eur. Microbiol. Soc.) Microbiol. Lett. 221:89-95.

Von Bodman, S. B., Majerczak, D. R., and Coplin, D. L.1998. A negative regulator mediates quorum sensing control of exopolysaccharide production in Pantoea stewartii subsp. stewartii. Proc. Natl. Acad. Sci. U.S.A. 95:7687-7692.

Wu, J., and Weiss, B. 1992. Two stage induction of the soxRS (superoxide response) regulon of Escherichia coli. J. Bacteriol. 174:3915-3920.

Zheng, M., Åslund, F., and Storz, G. 1998. Activation of the OxyR transcription factor by reversible disulfide bond formation. Science 279:1718-1722.

Zheng, M., Doan, B., Schneider, T.D., and Storz, G. 1999. OxyR and SoxRS regulation of Fur. J. Bacteriol. 181:4639-4643.

Zheng, M., Wang, X., Doan, B., Lewis, K. A., Schieder, T. D., and Storz, G. 2001. Computation-directed identification of OxyR DNA binding sites in Escherichia coli. J. Bacteriol. 183:4571-4579. 